\title{
Phosphate wasting disorders in adults
}

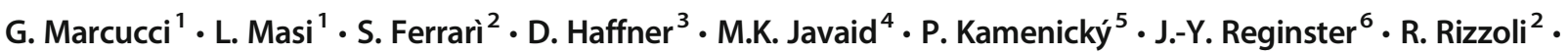 \\ M.L. Brandi ${ }^{1}$
}

Received: 22 March 2018 / Accepted: 19 June 2018

(C) International Osteoporosis Foundation and National Osteoporosis Foundation 2018

\begin{abstract}
A cause of hypophosphatemia is phosphate wasting disorders. Knowledge concerning mechanisms involved in phosphate wasting disorders has greatly increased in the last decade by the identification of phosphatonins, among them FGF-23. FGF23 is a primarily bone derived factor decreasing renal tubular reabsorption of phosphate and the synthesis of calcitriol. Currently, pharmacological treatment of these disorders offers limited efficacy and is potentially associated to gastrointestinal, renal, and parathyroid complications; therefore, efforts have been directed toward newer pharmacological strategies that target the FGF-23 pathway. This review focuses on phosphate metabolism, its main regulators, and phosphate wasting disorders in adults, highlighting the main issues related to diagnosis and current and new potential treatments.
\end{abstract}

Keywords FGF-23 $\cdot$ Hypophosphatemia $\cdot$ Osteomalacia $\cdot$ Phosphate wasting disorders $\cdot$ Rickets $\cdot$ Treatment

\section{Introduction}

Phosphorus is the most abundant anion in the human body and is essential for many biological functions. In humans, phosphate comprises $1 \%$ of total body weight. Eighty-five percent of the total phosphorous pool is localized in bones and teeth, complexed with calcium as hydroxyapatite crystals or as amorphous calcium phosphate, and $15 \%$ in soft tissue.

Phosphate is essential for energy storage and metabolism, nucleic acids, cell membrane function, and oxygen transport,

M.L. Brandi

marialuisa.brandi@unifi.it

1 Metabolic Bone Diseases Unit, Department of Surgery and Translational Medicine, University of Florence, Florence, Italy

2 Division of Bone Diseases, Geneva University Hospitals and Faculty of Medicine, Geneva, Switzerland

3 Department of Pediatric Kidney, Liver and Metabolic Diseases, Hannover Medical School, Hannover, Germany

4 Nuffield Department of Orthopaedics, Rheumatology and Musculoskeletal Sciences, University of Oxford, Oxford, UK

5 Service d'Endocrinologie et des Maladies de la Reproduction, Centre de référence des Maladies Rares du métabolisme du calcium et du phosphore, Hopital de Bicêtre - AP-HP, 94275 Le Kremlin-Bicêtre, France

6 Department of Public Health, Epidemiology and Health Economics, University of Liège, Liège, Belgium and it has a critical role in cell signaling, through phosphorylation reactions and enzyme activation. Moreover, phosphate has been shown to be involved in osteopontin gene expression, chondrocyte apoptosis, and vascular differentiation [1].

Normal serum phosphate levels vary greatly between childhood and adulthood. During infancy, higher serum phosphate levels are necessary for adequate bone mineralization; levels within the adult normal range are not sufficient for children and cause rickets [2].

For these reasons, phosphate has a key role for life, and phosphate homeostasis must be closely regulated, since hypoand hyperphosphatemia can cause severe problems in various organs and systems.

This review focuses on phosphate metabolism, its main regulators, and phosphate wasting disorders in adults, highlighting the main issues related to diagnosis and treatment.

\section{Phosphate homeostasis}

Under physiological conditions, a balance between intestinal absorption, renal excretion, and influx to and efflux from bone and soft tissues maintains an adequate phosphate homeostasis. Vitamin D, parathyroid hormone (PTH), and fibroblast growth factor-23 (FGF-23) are its main regulators [3].

The total plasma phosphate level is subdivided in inorganic and organic phosphate. The concentration of inorganic 
phosphate in the plasma is between 0.80 and $1.30 \mathrm{mmol} / \mathrm{l}$. Equilibrium between intracellular and extracellular phosphate is regulated by multiple factors. The $\mathrm{pH}$ state regulates the relative proportion of $\mathrm{HPO}_{4}{ }^{2-}$ and $\mathrm{H}_{2} \mathrm{PO}_{4}{ }^{-}$, and at normal $\mathrm{pH}$ the ratio is $4: 1$. In acidic conditions, this ratio decreases, whereas in alkaline states, it increases. Moreover, plasma phosphate levels are lowest in the morning and highest at night. Plasma phosphate can be lowered by a shift into cells by glucose ingestion, insulin, muscle activity, and hyperventilation. Depending on age, serum phosphate concentration varies. Infants have the highest concentration of phosphate compared with adolescents and adults. In children, there is a positive balance of $2-3 \mathrm{mmol} / \mathrm{day}$ in order to allow adequate growth, and in elderly subjects, there is a small negative balance, caused mainly by an age-related bone loss [1]. No gender differences in phosphate concentration in the age group 20-40 years have been described; however, phosphate concentration is lower in older men than in women. During pregnancy, plasma phosphate decreases [1].

Hypophosphatemia is defined by serum phosphate concentration $<0.80 \mathrm{mmol} / \mathrm{L}$ in adults and severe hypophosphatemia in case of $<0.30 \mathrm{mmol} / \mathrm{L}$. Several causes of hypophosphatemia have been identified [1]. Among these, phosphate wasting disorders causing hypophosphatemia are described in the following chapters.

\section{Intestinal absorption}

The human diet is usually abundant in phosphate, and the average intake of phosphate is about $20 \mathrm{mg} / \mathrm{kg} / \mathrm{day}$, but the net absorption of phosphorous is less than $900 \mathrm{mg}$ or $64 \%$ of total intake [4].

Phosphate absorption takes place throughout the small intestine and colon. There are two mechanisms of intestinal phosphate absorption: an active sodium-dependent pathway and a passive sodium-independent pathway. The passive transport of phosphate occurs by paracellular transport via tight junctions between cells, while the active transport occurs via the sodium-phosphate cotransporter NPT2b and possibly type 3 transporters PiT1 and PiT2 [1]. NPT2b is expressed in the brush border of enterocytes and belongs to the SLC34 solute carrier family [1]. During low-phosphate intake, absorption mostly occurs actively, whereas during high phosphate intake, passive absorption is prevalent [1].

Two important factors that regulate intestinal phosphate absorption are dietary phosphate intake and 1,25dihydroxyvitamin $\mathrm{D}_{3}\left[1,25(\mathrm{OH})_{2} \mathrm{D}_{3}\right]$ [1]. Active transport of phosphate is regulated by $1,25(\mathrm{OH})_{2} \mathrm{D}_{3}$, inducing the expression of NPT2b on the apical membrane of intestinal epithelial cells, and low-phosphate diets upregulate NPT2b expression, probably through the action of $1,25(\mathrm{OH})_{2} \mathrm{D}_{3}$, although the detailed mechanism of this regulation remains unclear $[5,6]$. Of note, FGF-23, the most important phosphatonin, with its cofactor Klotho, reduces the expression and activity levels of CYP27B1 (1-alpha-hydroxylase) and stimulates 24 hydroxylase, which, respectively, suppresses the production and increases the catabolism of active vitamin D. Therefore, reduced $1,25(\mathrm{OH})_{2} \mathrm{D}_{3}$ is associated with lower Pi absorption [1].

\section{Renal reabsorption and excretion}

In physiological conditions, the maintenance of phosphate balance is mainly guaranteed by urinary excretion of phosphate. About $90 \%$ of serum phosphate is ultra-filterable, and after glomerular filtration, the main site of phosphate reabsorption is the proximal convoluted tubule. The phosphate transports in the renal tubules are the type 2 sodiumphosphate cotransporters, NPT2a and NPT2c, encoded by SLC34A1 and SLC34A3 genes, respectively, and, to a much lower extent, the type 3 transporters. NPT2a and $2 \mathrm{c}$ are the main transporters responsible for controlling inorganic phosphate reabsorption in the renal proximal tubule [1]. NPT2a has a high affinity for phosphate, and its highest concentration is in the brush border membrane of the S1 segment of proximal convoluted tubule. On the other hand, NPT2c has a lower affinity for phosphate. Both transporters, NPT2a and NPT2c, allow the transport of phosphate into the cell, and the rate depends on the number of transporters available and on the sodium gradient across the luminal membrane, created by the $\mathrm{Na}^{+} / \mathrm{K}^{+}$-ATPase in the basolateral membrane [1].

The regulation of renal phosphate reabsorption is complex, and it is influenced by several factors, including dietary phosphate intake, hormones such as FGF-23 and PTH, and extracellular fluid (ECF) volume depletion.

Variations in dietary phosphate intake change the rate of renal phosphate reabsorption due to the changes of expression of phosphate transporters, such as NPT2a, NPT2c, and PiT2, independently of PTH and $1,25(\mathrm{OH})_{2} \mathrm{D}_{3}$ [7]. Moreover, a study described that NaPi-2-like transporters in the brain are regulated by both dietary phosphate and cerebrospinal fluid phosphate concentrations and, most significantly, that the central phosphate milieu can regulate renal NaPi-2 expression. Therefore, a role of NPT2a, localized in the brain, in the adaptive changes of phosphate reabsorption, through central transporters in the brain acting like phosphate sensors, is hypothesized [8].

The phosphaturic hormone FGF-23, with its cofactor Klotho, directly downregulates membrane expression of NPT2a by serine phosphorylation of the scaffolding protein $\mathrm{Na}^{+} / \mathrm{H}^{+}$exchange regulatory cofactor (NHERF1) via extracellular signal-regulated kinase $1 / 2$ and serum/glucocorticoidregulated kinase-1 signaling in proximal tubular segments [9]. Therefore, the suppression of renal cotransporter by FGF-23 impairs the renal reabsorption of phosphate, causing a reduction of serum phosphate levels. In addition to FGF-23, other "phosphatonins," including secreted frizzled-related 
protein 4 (sFRP-4), fibroblast growth factor 7 (FGF-7), and matrix extracellular phosphoglycoprotein (MEPE), are hormones that regulate phosphate metabolism by reducing renal phosphate reabsorption. The description of the major role of FGF-23 will be discussed in the next chapter.

In addition to the FGF-23, the regulators of phosphate reabsorption are mostly dietary $\mathrm{Pi}$ intakes and to a lesser extent $\mathrm{PTH}$, which, through interaction with $\mathrm{PTH} / \mathrm{PTHrP}$ receptors (highly expressed in renal tubules), determines an acute effect of a rapid endocytosis and degradation of NPT2a transporters and also seems to regulate NPT2c transporters [10].

Some studies show that $1,25(\mathrm{OH})_{2} \mathrm{D}_{3}$ stimulates phosphate reabsorption, acting directly on the proximal tubule through the induction of NPT2a and NPT2c, and appears to have a permissive role in the action of PTH on phosphate reabsorption [11].

Lastly, in hemodialyzed patients with chronic kidney disease (CKD), the levels of sclerostin, a potent inhibitor of bone formation, tend to be higher compared to those of control subjects, although the pathophysiological relevance of circulating levels remains undetermined. A study evaluated the association between sclerostin and phosphate levels besides PTH, biomarkers of bone turnover, vascular calcifications, and mortality. In a multivariate model, a positive association was described with phosphate, and this association was independent of PTH and FGF-23 levels. This interesting result will require additional research in the future [12].

Figure 1 shows phosphate metabolism and its regulators.

\section{FGF-23 and its multisystemic actions}

FGF-23 is a glycoprotein with 251 amino acids. It is primarily secreted by osteocytes, and to a lesser extent by osteoblasts, or venous sinusoids of the bone, endocrine organs (e.g., parathyroid glands, ovaries, testes), heart, hypothalamus, cortex, hippocampus, caudate putamen, amygdala, and ventrolateral thalamic nucleus, although the physiological relevance of FGF23 produced by these other tissues has not yet been determined $[13,14]$. Under physiological conditions, FGF-23 is almost exclusively produced by osteocytes and osteoblasts in response to high serum phosphate levels and $1,25(\mathrm{OH})_{2} \mathrm{D}_{3}[15]$.

The FGF-23 gene is located on chromosome 12p13.29. The mature protein, FGF-23 (25-251), is secreted into circulation upon cleavage of the signal sequence comprising 24 amino acids and O-glycosylation by UDP- $N$-acetyl-alpha-D-galactosamine: polypeptide $N$-acetylgalactosaminyltransferase 3 (GALNT3) [16, 17]. The O-glycosylation occurs in the 162228 region of FGF-23, and this post-translational modification protects it from cleavage by subtilisin-like proprotein convertases when using recombinant peptides in vitro. Intact FGF-23 is cleaved by a furin proprotein convertase into inactive $\mathrm{N}$ - and C-terminal fragments, and FGF-23 is then removed by the kidney. The signal peptide with 24 amino acids is in the
N-terminal portion of the FGF-23 protein, and next to the signal peptide is the FGF homology region. Its $\mathrm{C}$-terminal peptide binds in a coordinated fashion to FGF receptors (FGFR) in the tissue as well its cognate coligand Klotho, which exists both as a transmembrane protein and a soluble form, the latter of which regulates phosphorus metabolism with FGF-23 [18-20].

Receptor specificity for FGF-23 relies on its interaction with FGF receptors (FGFR1, 3, or 4) and the coreceptor $\alpha$ Klotho, resulting in activation of the mitogen-activated protein kinase (MAPK) pathway and phospho-ERK. Both the Nterminal and C-terminal portions of FGF-23 are necessary for this complete interaction [18].

\section{Regulation of FGF-23}

Although the regulation of FGF-23 has been extensively examined, it has not yet been fully elucidated. However, the main regulation of FGF-23 is based on systemic $\left[1,25(\mathrm{OH})_{2} \mathrm{D}_{3}\right.$ and serum phosphate $]$ and local factors $[1,21]$.

Serum phosphate and $1,25(\mathrm{OH})_{2} \mathrm{D}_{3}$ are both positive regulators of FGF-23; when serum phosphate or vitamin D levels are high, FGF-23 level is elevated to increase renal phosphate excretion and to decrease active $1,25(\mathrm{OH})_{2} \mathrm{D}_{3}$ levels. In particular, $1,25(\mathrm{OH})_{2} \mathrm{D}_{3}$ regulates $\mathrm{FGF}-23$ via both vitamin $\mathrm{D}$ receptor (VDR) dependent and independent mechanisms. Indeed, the active form of vitamin $\mathrm{D}$ appears to increase FGF-23 expression levels in vitro and in vivo by activating the VDR [22], and FGF-23 in turn suppresses $1,25(\mathrm{OH})_{2} \mathrm{D}_{3}$ [18]. The effect of oral phosphate on FGF-23 concentration is not fully clear [23]. It remains to be elucidated whether the induction of FGF-23 is exerted by Pi itself or mediated through additional factors such as PTH.

Another feature of FGF-23 is that it is regulated in a manner that involves circadian rhythms, and this rhythmic profile of FGF-23 may be influenced by the timing of food intake driven sympathetic activation, as described in mice [24, 25].

The role of PTH in the regulation of FGF-23 has not been fully clarified, although the FGF receptor and its cofactor Klotho are expressed in parathyroid glands [26]. In the skeleton, PTH has been suggested to have a role as positive regulator of the expression of FGF-23, given that, in case of high PTH levels such as CKD and Jansen metaphyseal chondrodysplasia, caused by a mutation in the PTH1R gene, circulating FGF-23 levels were reportedly elevated [27]. However, the data from in vitro studies for the induction of FGF-23 by PTH are limited, and FGF-23 levels were previously reported to be similar in patients with primary hyperparathyroidism and healthy controls [28]. Experimental studies have shown an inhibitory effect of FGF-23 on both PTH production and secretion. A recent study investigated this relationship using wistar rats allocated to treatment with intravenous recombinant FGF-23 and inhibition of the FGF receptor in case of normocalcemia or acute hypocalcemia [29]. This 


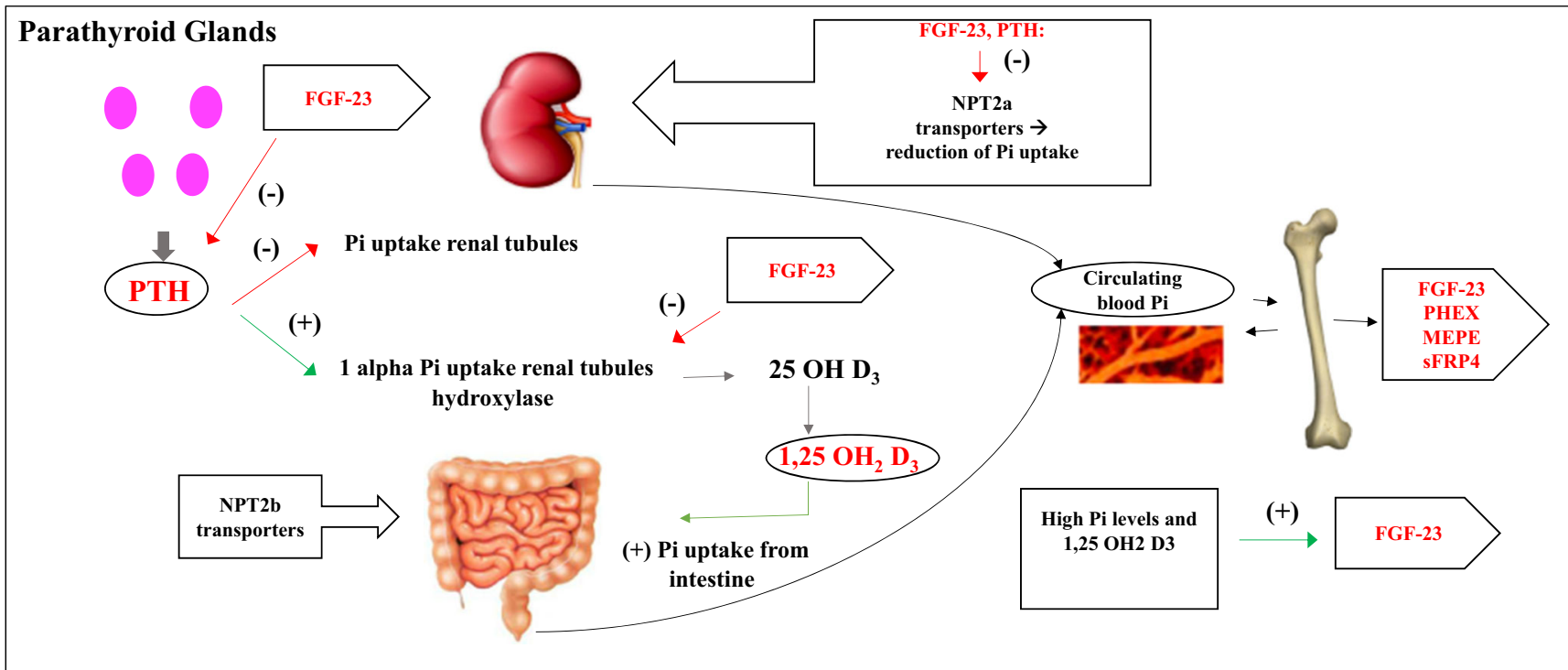

Fig. 1 This figure shows phosphate metabolism and its regulators

study described that FGF-23 rapidly inhibited PTH secretion in normocalcemia and that this effect was blocked by inhibition of the FGF receptor. On the other hand, in case of acute hypocalcemia, there was no effect, when increased PTH secretion is needed to restore the calcium homeostasis [29].

Regarding bone mineralization, a recent study showed that FGF-23, in a Klotho-independent manner, is able to act through FGF receptor-3 to regulate osteopontin secretion indirectly by suppressing alkaline phosphatase transcription and phosphate production in osteoblastic cells. Therefore, FGF-23, derived by osteocytes, may form an autocrine/paracrine feedback loop for the local fine-tuning of bone mineralization [30].

In addition to phosphorus, $1,25(\mathrm{OH})_{2} \mathrm{D}_{3}$, and $\mathrm{PTH}$, there are several factors, produced in the bone, that have an important role in FGF-23 regulation, encoded by phosphate regulating endopeptidase homolog X-linked (PHEX), dentin matrix acidic phosphoprotein 1 (DMP-1), and ectonucleotide pyrophosphatase/phosphodiesterase 1 (ENPP1) genes [31, 32]. Among these, dentin matrix acidic phosphoprotein (DMP1), an inducer of mineralization of bone, is able to inhibit FGF-23, most likely through indirect mechanisms [33]. Deletion of the PHEX, highly expressed in osteocytes and osteoblasts, leads to high FGF-23 levels, although the exact mechanism remains unclear. On the other hand, the proteolytic cleavage of MEPE releases the C-terminal acidic serineaspartate-rich MEPE (ASARM) peptide, with an inhibitory effect on mineralization and renal phosphate reabsorption [34]. MEPE and ASARM may influence FGF-23 by decreasing PHEX activity [34].

In bone, it has also been shown that FGF-23 synthesis and catabolism are regulated by several additional factors, including calcium, PTH, the renin-angiotensin-aldosterone system (RAAS), oxidative stress, inflammation, and parameters of iron metabolism as well as parenteral iron supplementation $[35,36]$.

\section{Classical and non-classical FGF-23 actions}

The classical actions of FGF-23 involve the downregulation of the activity and expression of the sodium-dependent phosphate transporters NPT2a and NPT2c in the proximal tubule apical membrane, reducing the renal phosphate reabsorption [37]. Moreover, FGF-23 inhibits 1 alpha-hydroxylase independently of PTH, reducing the renal synthesis of $1,25(\mathrm{OH})_{2} \mathrm{D}_{3}$, as well as stimulating the 25 -vitamin D-24 hydroxylase [37].

Non-classical actions of FGF-23 include other renal effects, such as stimulation of distal tubular sodium and calcium reabsorption, suppression of the angiotensin converting enzyme-2 (ACE2) transcription in the kidney, and at the parathyroid gland it may inhibit PTH secretion [35]. The biological effects of C-terminal FGF-23 are not well known, but it may have inhibitory effects on the actions of intact FGF-23 [35]. Moreover, FGF-23 levels appear to be associated with increased cardiovascular comorbidity and cognitive dysfunction in CKD patients. FGF-23 directly induces left ventricular hypertrophy via activation of FGFR4/calcineurin/nuclear factor of activated T cell (NFAT) signaling pathway in rodents and most likely in patients with CKD. FGF-23 signaling negatively affects neutrophil recruitment and host defense during CKD. It directly acts on hippocampal neurons and may thereby impair memory function and learning capacity in CKD patients [35]. In case of early CKD, a high FGF-23 serum concentration is the first metabolic alteration detectable [35]. FGF-23 serum concentrations rise progressively with declining renal function and, consequently, $1,25(\mathrm{OH})_{2} \mathrm{D}_{3}$ deficit, secondary 
hyperparathyroidism, and, presumably, Klotho deficiency [35]. These elevated FGF-23 levels tend to maintain serum phosphate concentrations within normal limits in CKD patients until their renal function becomes markedly restricted [35].

\section{Other phosphatonins}

The protein secreted frizzled protein 4 (sFRP4) is ubiquitously expressed and circulates as a $48-\mathrm{kD}$ protein. As the expression of this gene is increased in tumor-associated osteomalacia (TIO), it has been suggested to be a phosphatonin. FGF-7 has been shown to be increased in TIO, but its exact role in phosphate homeostasis is yet to be determined. MEPE is a 525 amino acid protein expressed in bone, salivary glands, and dental tissue and expressed in tumor-associated osteomalacia [38].

\section{FGF23 assays}

Currently, several FGF-23 immunoassays are available, but they are usually reserved for research purposes. Figure 2 shows assay kits for measuring circulating FGF-23. They detect intact FGF-23 (iFGF-23) or both iFGF-23 and C-terminal FGF-23 (cFGF-23) portions, and most assays are characterized by the presence of a double antibody sandwich ELISA with colorimetric reading. Antibodies of iFGF-23 detect epitopes within both the amino-terminal and the C-terminal fragments, and the cFGF-23 assay is based on antibodies detecting two different epitopes in the C-terminal portion. In patients with different stages of renal function, it is not yet clear if the cFGF-23 assay provides comparable sensitivity to that for iFGF-23. The use of only one assay may cause a significant underestimation; however, a study described that measurements obtained with iFGF23 and cFGF-23 assays would reflect the same circulating moiety. Therefore, in the future, additional investigations are needed to determine whether this applies regardless of kidney function [39]. Recently, the performance of a new automated assay for iFGF-23 on the DiaSorin Liaison platform, which is approved for clinical use, has been evaluated in 908 healthy French subjects with disorders of phosphate metabolism and in adult patients (18-89 years) with CKD [40]. The results showed that this new, fully automated immunoassay for iFGF-23 available on a platform, now approved for clinical use by the European Community authorities, had excellent analytical characteristics. Adult reference values were established and the expected concentrations in patients with various disorders of phosphate metabolism and in patients with CKD were obtained. This assay uses three monoclonal antibodies: one coated on microparticles and directed against the $\mathrm{N}$-terminal portion of the iFGF-23; another, labeled with fluoresceine, directed against the C-terminal fragment; and the third, bound with isoluminol, directed against fluoresceine. This assay is reserved for the measurement of iFGF-23 in EDTA plasma. The availability of this new assay appears to allow real improvement for the laboratories and clinicians/ researchers involved in this field [40].

\section{Phosphate wasting disorders in adults}

The causes of hypophosphatemia due phosphate wasting are subdivided into genetic and acquired forms. The

Kainos and Immunotopics Human Intact FGF-23 ELISA Kits have antibodies directed to the N- and C-terminal (C-term) portions, detecting only the intact molecule. Immunotopics ${ }^{\circledR}$ Human FGF-23 (C-term) ELISA kit identify only C-term fragment, detecting both the intact molecule and carboxyl portions.

\section{Kainos ${ }^{\circledR}$ FGF-23 ELISA kit $\rightarrow$}

\section{Immunotopics ${ }_{\circledR}$ Human Intact FGF-23 ELISA kit $\rightarrow$}

Immunotopics® Human FGF-23 (C-term) ELISA kit $\rightarrow$
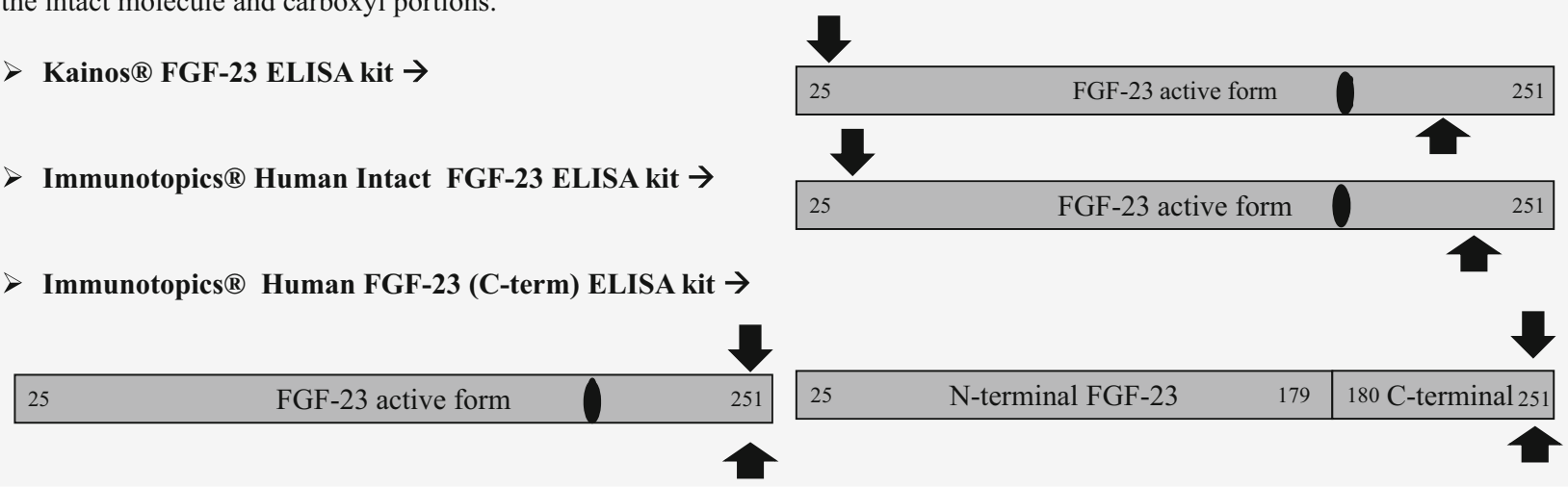

FGF-23: 32-kDa protein of 251 amino acids, with a leader sequence of 24 amino acids encoding for a signal peptide. There are two circukating FGF-23 forms: active and inactive forms. The inactive forms derived from $\rightarrow$ a proteolytic cleavage between Arg 179 and Ser 180, due to protein convertases during processes of secretion, generating N-terminal and C-terminal fragments. FGF-23 assay kits: detect intact FGF-23 alone or both intact and C-terminal FGF-23 fragments. Most FGF-23 assays consisting of a double antibody sandwich ELISA with colorimetric reading. Antibody tests detect epitopes within the amino-terminal and the carboxyl-terminal fragments. Then, the C-terminal FGF-23 assay measures both the intact molecule and the large carboxyl terminal portion of FGF-23. Reference: [39]

Fig. 2 This figure illustrates epitopes recognized by the FGF-23 assays 
genetic forms, and TIO, are discussed below. Table 1 shows main features regarding etiology, biochemical exams, and treatment of genetic phosphate wasting disorders, TIO, and hypophosphatemia due to renal transplantation.

Moreover, among the main acquired forms of hypophosphatemia due to phosphate wasting, there are also hypophosphatemia related to hepatic surgery and alcohol or drug-induced hypophosphatemia.

After hepatic surgery, hypophosphatemia is often described. Serum phosphate levels usually reduce on the first or second post-operative day and normalize by the ninth day. Renal phosphate loss, independently of FGF-23, FGF7, sFRP4, or PTH-related effects, and the uptake of phosphate by rapidly regenerating liver cells were hypothesized as possible mechanisms; however, the pathogenesis for hypophosphatemia post-hepatic surgery is not well known [1].

The mechanisms that cause acute and chronic alcoholism-induced hypophosphatemia are mainly based on increased renal phosphate loss, due to alcohol, acidosis and associated magnesium depletion; reduced phosphate intake, caused by poor diet, anorexia, gastritis, vomiting and diarrhea; and, last, increased cellular uptake for hyperventilation, intravenous glucose and bicarbonate, catecholamine release, and anabolic state during recovery [1].

Lastly, some drugs, which are listed below, can cause druginduced hypophosphatemia, due at least partially to increased renal phosphate loss. Sympatomimetics, dopamine, and theophylline can cause hypophosphatemia by increased renal loss of phosphate [1]. The antiviral drugs cidofovir and adefovir can induce Fanconi syndrome [1]. Intravenous administration of saccharated iron can cause hypophosphatemia, due to an increase in FGF-23 for inhibition of its degradation and, probably, a direct effect of iron on renal tubules causing phosphate wasting [1]. Paracetamol in toxic doses can also determine hypophosphatemia. The mechanism is due to transcellular shift and an increased renal phosphate loss [1]. Moreover, other drugs can induce increased renal loss of phosphate, such as rapamycin, ifosfamide, anti-EGF treatment, tyrosine kinase inhibitors (e.g., imatinib), bisphosphonate, acetazolamide (carbonic anhydrase inhibitors), anticonvulsants, diuretics, estrogens, suramin, and azacitidine [1].

\section{X-linked hypophosphatemic rickets}

\section{Definition}

$\mathrm{X}$-linked hypophosphatemic rickets (XLH) is a rare inherited form of renal phosphate wasting disorder, but among the inherited forms, it is the most common with an estimated prevalence of $1 / 20,000[41,42]$.

\section{Cause}

XLH is caused by a variety of inactivating mutations in the PHEX gene, located on the $\mathrm{X}$ chromosome, which is expressed in osteocytes and odontoblasts [43]. Indeed, this gene encodes an endopeptidase, which is thought to degrade FGF-23, and in XLH this endopeptidase appears to be inactive; however, the exact mechanism is not well known [44]. FGF-23 was initially referred to as a substrate of PHEX, but subsequent research found that FGF-23 is not a direct substrate of PHEX [45]. PHEX protein is expressed in various tissues, including the kidney, but is most abundant in mature osteoblasts and odontoblasts and it is important for normal matrix mineralization. It is now thought that it might control mineralization by binding proteins such as DMP-1 and matrix extracellular phosphoglycoprotein, which are both members of the SIBLING proteins and contain ASARM peptides, preventing their proteolysis and the release of ASARM peptides, which inhibit mineralization [46]. There are over 170 different mutations in PHEX (e.g., missense, non-sense, deletions, and splice site mutations); however, a clear genotypephenotype correlation has not been described [46]. Other genetic and environmental factors may influence the clinical manifestations of this disease. In some cases, a PHEX gene mutation cannot be detected, and sporadic cases are common. The XLH diagnosis is not necessarily based on genetic mutation but can also be made from appropriate biochemical studies.

\section{Clinical expression}

Rickets is the presenting clinical feature of XLH in children; however, clinical manifestations have a wide variation in severity, ranging from mild hypophosphatemia to severe bone disease [32]. Females usually have less relevant bone involvement than males, perhaps due in part to a difference in relative gene dosage [4]. The onset of clinical manifestation is generally during late infancy. Initial clinical features of XLH may be recognized as a delay in walking in the first years of life and, subsequently, short stature, reduced growth rate, and bone deformity [4]. Subjects with XLH can develop skeletal deformities that primarily include bowing of the long bones and widening of the metaphyseal region, more commonly at costochondral junctions (rachitic rosary). Genua vara and valga, coxa vara, and femoral and crural bowing are frequently present [4]. In childhood, early pharmacological treatment of high-dose vitamin $\mathrm{D}$ and phosphate supplementation may prevent or at least reduce long-bone deformities and facilitate healing of pseudofractures [4]. However, many patients, despite adequate medical management, or because of delayed diagnosis, still develop significant bone deformities (especially of the lower extremities), requiring corrective surgical treatment [4]. 
Table 1 Main features regarding etiology, biochemical exams, and treatments of genetic phosphate wasting disorders, tumor-induced osteomalacia, and hypophosphatemia due to renal transplantation

Disorders that are FGF-23-mediated

\begin{tabular}{|c|c|c|c|c|c|}
\hline Disorders & Abbreviation & Gene & Mechanism & Serum calcium & Urine calcium \\
\hline $\begin{array}{l}\text { X-linked hypophosphatemic } \\
\text { rickets }\end{array}$ & XLH & PHEX & FGF-23 increased & Normal & Normal/low \\
\hline $\begin{array}{l}\text { Autosomal dominant } \\
\text { hypophosphatemic rickets }\end{array}$ & ADHR & $F G F-23$ & FGF-23 increased & Normal & Normal/low \\
\hline $\begin{array}{l}\text { Autosomal recessive } \\
\text { hypophosphatemic rickets }\end{array}$ & ARHR & $D M P 1 / E N P P 1$ & FGF-23 normal/increased & Normal & Normal/low \\
\hline Tumor-induced osteomalacia & TIO & (Acquired) & FGF-23 increased & Normal & Normal/low \\
\hline $\begin{array}{l}\text { Hypophosphatemia due to } \\
\text { renal transplantation }\end{array}$ & & (Acquired) & $\begin{array}{l}\text { Increase of renal phosphate loss. } \\
\text { Contributing factors: high levels } \\
\text { of serum FGF- } 23 \text { and PTH. } \\
\text { Tacrolimus and high-dose } \\
\text { steroids tend to decrease } \\
\text { the expression of NPT2a }\end{array}$ & Normal & Normal/low \\
\hline $\begin{array}{l}\text { McCune-Albright } \\
\text { Disorders that are non-FGF-23- } \\
\text { mediated }\end{array}$ & & GNAS1 & FGF-23 increased & Normal/high & Normal \\
\hline $\begin{array}{l}\text { Hereditary hypophosphatemic } \\
\text { rickets with hypercalciuria }\end{array}$ & HHRH & SLC34A3 & $\begin{array}{l}\text { Proximal tubular phosphate } \\
\text { wasting }\end{array}$ & Normal & High \\
\hline Fanconi syndrome & & Various (SLC34A1) & $\begin{array}{l}\text { Impairment of function of the } \\
\text { proximal tubules }\end{array}$ & $\begin{array}{l}\text { Variable: normal/ } \\
\text { low/high }\end{array}$ & Normal/high \\
\hline
\end{tabular}

Disorders that are FGF-23-mediated

\begin{tabular}{|c|c|c|c|c|c|}
\hline Disorders & Serum PTH & Serum phosphate & Tmp/GFR & Serum $1,25(\mathrm{OH})_{2} \mathrm{D}_{3}$ & $\begin{array}{l}\text { Standard treatments of } \\
\text { hypophosphatemia }\end{array}$ \\
\hline $\begin{array}{l}\text { X-linked hypophosphatemic } \\
\text { rickets }\end{array}$ & Normal/high & Low & Low & Low or inappropriate & $\begin{array}{l}\text { Phosphate supplementation } \\
\text { and calcitriol or alfacalcidiol }\end{array}$ \\
\hline $\begin{array}{l}\text { Autosomal dominant } \\
\text { hypophosphatemic rickets }\end{array}$ & Normal & Low & Low & Low or inappropriate & Like XLH \\
\hline $\begin{array}{l}\text { Autosomal recessive } \\
\text { hypophosphatemic rickets }\end{array}$ & Normal/high & Low & Low & Low or inappropriate & Like XLH \\
\hline Tumor-induced osteomalacia & $\begin{array}{l}\text { Variable: normal/ } \\
\text { low/high }\end{array}$ & Low & Low & Low & $\begin{array}{l}\text { - Surgery (resection of tumor) } \\
\text { - Phosphate supplementation } \\
\text { and calcitriol or alfacalcidiol }\end{array}$ \\
\hline $\begin{array}{l}\text { Hypophosphatemia due to } \\
\text { renal transplantation }\end{array}$ & Normal/high & Low & Low & Normal/low & $\begin{array}{l}\text { Phosphate supplementation } \\
\text { and calcitriol or alfacalcidiol }\end{array}$ \\
\hline McCune-Albright & Normal/high & Normal/low & Normal/low & Normal/low & $\begin{array}{l}\text { Phosphate supplementation } \\
\text { and calcitriol or alfacalcidiol }\end{array}$ \\
\hline \multicolumn{6}{|l|}{$\begin{array}{l}\text { Disorders that are non-FGF-23- } \\
\text { mediated }\end{array}$} \\
\hline $\begin{array}{l}\text { Hereditary hypophosphatemic } \\
\text { rickets with hypercalciuria }\end{array}$ & $\begin{array}{l}\text { Variable: normal/ } \\
\text { low }\end{array}$ & Low & Low & High & Phosphate supplementation \\
\hline Fanconi syndrome & Normal/high & Normal/low & Normal/low & Normal/low & $\begin{array}{l}\text { Phosphate supplementation } \\
\text { and calcitriol or alfacalcidiol }\end{array}$ \\
\hline
\end{tabular}

References: [1, 32, 41, 49]

In adulthood, patients tend to develop osteomalacia with bone pain, degenerative joint disease characterized by joint pain, stiffness, and decreased joint mobility due to enthesopathy (calcified ligaments and teno-osseous junctions), and dental disease, such as tooth decay and dental abscesses. Enthesopathy and osteoarthritis are among the most significant complications and complaints of adult patients affected by XLH. The pathogenesis of enthesopathy, craniosynostosis, and tendency for hyperparathyroidism is not well explained [32]. However, recent pieces of evidence of expression of FGFR and Klotho in sites where enthesopathy develops suggest that FGF-23 could have a specific role [47]. Medical treatment can improve these abnormalities, but they cannot be completely resolved. In particular, enthesopathy 
does not appear to be influenced in either a positive or negative way by standard treatment of XLH.

Dental abscesses of deciduous and permanent teeth are a common clinical complication in these patients and, often, after repeated infection, permanent teeth are lost in youngadulthood. Moreover, root dysplasia and enlarged pulp chambers can be identified by radiographic examinations. There are structural abnormalities that increase the risk of dental abscesses, such as poorly mineralized and thinner dentin and cementum layers, and possibly enamel abnormalities [48]. Regarding the pathogenesis, FGF-23 is expressed in odontoblasts, and hypophosphatemia may contribute to the dental pathology [48].

Adult XLH patients, as well as in other hypophosphatemic rickets, can present with variable hearing loss [49]. These subjects may have mild-to-severe sensorineural hearing loss (affecting especially low and high frequencies). X-ray exams show generalized osteosclerosis and thickening of the petrous bone, with narrowed internal auditory meatus. In some cases, tinnitus and vertigo can be associated with low frequency hearing loss [49].

\section{Biochemical expression}

XLH is typically characterized by hypophosphatemia, renal phosphate wasting, reduced tubular maximal reabsorption of phosphate adjusted for glomerular filtration rate (TmP/GFR), and inappropriately low or normal $1,25(\mathrm{OH})_{2} \mathrm{D}_{3}$ serum concentrations, while serum 25-vitamin D [25-(OH)D] is usually normal. Serum alkaline phosphatase (ALP) activity is elevated, principally from a bone source, and it represents an important parameter for disease control, as well as efficacy of therapy [4]. Generally, patients affected by XLH have normal serum calcium levels; however, secondary hyperparathyroidism is common in this disease, both without treatment with phosphate and as a potential consequence of phosphate treatment. Additional laboratory findings that could lead to diagnosis include high plasma levels of FGF-23, although a normal level of FGF-23 of medium-high range would be considered inappropriate for this degree of hypophosphatemia and would also be consistent with a diagnosis of XLH [4]. It is important to consider other differential diagnoses, as discussed below, leading to hypophosphatemic hyperphosphaturic rickets, especially when a familial history is present [4].

\section{Other diseases with features of hypophosphatemia due to renal phosphate wasting}

In addition to XLH, other diseases with features of hypophosphatemia due to impaired proximal tubular reabsorption of phosphate, mediated by FGF-23 excess, include autosomal-dominant hypophosphatemic rickets (ADHR), autosomal recessive hypophosphatemic rickets (ARHR), tumorinduced osteomalacia (TIO), and hypophosphatemia associated with fibrous dysplasia of bone/McCune-Albright syndrome (see Table 1) [1].

Several other rare disorders may variably manifest as FGF23-associated hypophosphatemia as a clinical feature; such disorders include epidermal nevus syndrome, neurofibromatosis, osteoglophonic dysplasia, hypophosphatemic rickets with hyperparathyroidism, and hypophosphatemia associated with parenteral iron therapy [11, 50, 51]. In contrast, hereditary hypophosphatemic rickets with hypercalciuria (HHRH), and Fanconi syndrome are FGF23-independent forms of renal phosphate wasting (see Table 1).

\section{Autosomal-dominant hypophosphatemic rickets}

\section{Definition}

ADHR is a rare disease with clinical and biochemical findings similar to XLH [52].

\section{Cause}

ADHR is caused by a missense mutation in $F G F-23$ gene itself, leading to alteration in the RXXR furin protease recognition site, that renders FGF-23 resistant to proteolytic cleavage [32]. Mutant FGF-23 proteins have increased stability, are more active than wild-type FGF-23, in vivo, and in these patients are likely present at high levels [53]. Therefore, elevated circulating concentrations of FGF-23 are caused by its reduced degradation.

\section{Clinical expression}

The expression of the disease can vary, and in some cases, despite carrying the gene mutation, hypophosphatemia never develops $[44,54]$. Patients, manifesting the disease in childhood, usually develop short stature, rickets, lower extremity deformities, bone pain, and dental abscesses. However, in some cases, the children show spontaneous resolution of symptoms during adulthood. In adulthood, patients can have symptoms similar to patients with TIO, developing hypophosphatemic osteomalacia, and clinical manifestations can include also bone pain, weakness, and fractures/ pseudofractures [54]. Moreover, it has been described that most patients who develop the disease in adulthood are women, and pregnancy appears to be a trigger of the onset of symptoms [54]. Some affected females have demonstrated delayed expression of the disease features; in contrast, some individuals have lost the renal phosphate wasting defect after puberty. Currently, it is not clear why patients only sometimes generate inappropriate FGF-23 and hypophosphatemia. However, 
some studies suggested that, both in ADHR patients and in a mouse model of ADHR, iron status may regulate FGF-23 metabolic pathways and that low iron status results in increased FGF-23 mRNA [54, 55]. As the risk for iron deficiency may increase at the time of puberty, a potential for increased expression of FGF-23 during this time exists and may lead to the development of a subclinical disorder [55].

\section{Biochemical expression}

In patients with active disease, the biochemical profile is characterized by hypophosphatemia, phosphaturia, and inappropriately normal or low $1,25(\mathrm{OH})_{2} \mathrm{D}_{3}$ concentrations, as in XLH [54]. Some patients alternate between periods of hypophosphatemia and normophosphatemia, coinciding with differences in FGF-23 concentrations $[55,56]$.

\section{Autosomal recessive hypophosphatemic rickets}

\section{Definition}

ARHR is another rare hereditary renal phosphate wasting disorder characterized by hypophosphatemia, rickets, and/or osteomalacia and slow growth $[32,52]$.

\section{Cause}

ARHR type 1 is due to a mutation in the gene encoding the protein DMP1, a member of the small integrin-binding ligand $\mathrm{N}$-linked glycoprotein family of extracellular matrix proteins that augment mineralization. Loss of function of DMP-1 causes an increased transcription of FGF-23 by osteocytes; however, the mechanism is not fully clear [31, 44]. Of note, DMP-1 is widely expressed but particularly abundant in bone, where it is synthesized by osteoblasts, and it is involved in the regulation of transcription in undifferentiated osteoblasts. Moreover, another form of ARHR was identified as ARHR type 2 caused by an inactivating mutation in the ENPP1 gene. The gene product ectonucleotide pyrophosphatase/ phosphodiesterase 1 is a cell surface enzyme responsible for generating inorganic pyrophosphate that is able to inhibit bone. Loss-of-function mutations in ENPP1 can cause generalized arterial calcification of infancy mineralization [57].

\section{Clinical expression and biochemical expression}

Clinical and biochemical features are similar to ADHR and $\mathrm{XLH}$, with the exception of a relatively higher bone mineral density (BMD) [32]. Indeed, clinical manifestations include rickets, skeletal deformities, dental defects, sclerotic bone lesions, and enthesopathies. Affected subjects show signs of rickets/osteomalacia later during childhood and even in adulthood [32]. In these patients, FGF-23 concentrations are high, but the exact mechanism has yet to be understood.

\section{Hereditary hypophosphatemic rickets with hypercalciuria}

HHRH is a hereditary hypophosphatemic disorder resulting from specific transporter mutations [58]. It is a rare autosomal recessive disorder, due to a mutation in the $S L C 34 A 3$ gene, which encodes the NPT2c renal phosphate cotransporter, resulting in primary renal phosphate loss [58].

This disease is characterized by hypophosphatemia, rickets, osteopenia/osteomalacia, and renal phosphate wasting, and, in contrast to XLH, urinary calcium excretion can be considerably elevated, and circulating PTH is usually low to low-normal. In this condition, FGF-23 is appropriately downregulated and the hypophosphatemia causes the expected increase in $1,25(\mathrm{OH})_{2} \mathrm{D}_{3}$ levels [59]. This finding differs from the FGF23-mediated decrease in expression of CYP27B1 (encoding 1a-hydroxylase) and thus low or normal levels of $1,25(\mathrm{OH})_{2} \mathrm{D}_{3}$ observed in XLH, ADHR, and ARHR. Both the human disorder of HHRH due to NPT2c mutations and the mouse models of npt $2 \mathrm{c}$ or npt $2 \mathrm{a}$ deficiency show that increased $1,25(\mathrm{OH})_{2} \mathrm{D}_{3}$ levels result in increased calcium absorption and consequent hypercalciuria [58]. In addition to phosphate wasting and rickets, renal stones may occur, and the hypercalciuria is likely to play a role in stone formation [60].

\section{Fibrous dysplasia and McCune-Albright syndrome}

Fibrous dysplasia (FD) is a genetic, non-inherited disorder caused by somatic activating missense mutations of the signaling protein GS alpha (GNAS1 gene), encoding the $\alpha$ subunit of the stimulatory $G$ protein, Gs. This is a nonneoplastic disease affecting the skeleton as monostotic or polyostotic forms or in variable combinations with endocrine and cutaneous abnormalities in case of McCune-Albright syndrome (MAS). Hypophosphatemic rickets/osteomalacia is a rare clinical complication of FD/MAS. In approximately $50 \%$ of FD/MAS patients, renal phosphate wasting is reported [61]. Indeed, some patients develop hypophosphatemia, high FGF-23 levels, and a decreased TmP/GFR, though the mechanisms responsible for FGF-23 overproduction by FD tissue are unknown [62, 63]. Hypophosphatemia is a key predictor of future fragility fracture risk for people with FD/MAS [62]. 99Tc scintigraphy is useful when bone FD is suspected [4]. 


\section{Tumor-induced osteomalacia}

\section{Definition}

TIO is a rare paraneoplastic syndrome characterized by hypophosphatemia due to renal phosphate wasting in adult subjects and osteomalacia. This disease may be associated with mesenchymal tumors. Hypophosphatemia is caused by unregulated oversecretion of FGF-23, derived usually by small and mesenchymal tumors. The incidence and prevalence are not known; in literature, more than 300 cases of TIO have been reported [38].

\section{Cause}

The diagnosis is commonly delayed for years, due to underrecognition of the disease. The most common tumor associated to TIO is hemangiopericytoma, followed by other tumors, such as hemangioma, sarcomas, myxoma, ossifying fibromas, granulomas, giant cell tumors, neurofibromatosis, schwannoma, and prostatic tumor and osteoblastomas [64]. Most of the tumors are slow growing, benign, and extremely vascular mesenchymal tumors involving soft tissue and bone. The prototypical phosphaturic mesenchymal tumor (mixed connective tissue variant) contains neoplastic cells that are spindled to stellate in shape, normochromatic with small nuclei and indistinct nucleoli. A prominent feature of these tumors is an intrinsic microvasculature with an admixture of vessel size and vascular pattern [64]. These tumors can occur from head to toe, and unusual locations have included the nasopharynx, the maxilla, and the palm of the hand. Occasional malignant tumors have been reported $[1,38]$.

TIO tumors can be subdivided into four different types: mixed connective tissue variant (phosphaturic mesenchymal tumor mixed connective tissue variant), osteoblastoma-like variant, non-ossifying fibroma-like variant, and ossifying fibroma-like variant. The first group is diagnosed in 70-80\% of TIO cases and comprises neoplasias containing primitive stromal cells, prominent vessel, and osteoclast-like giant cells. These tumors usually occur in bones or soft tissues and are typically benign in behavior, except some cases of malignant variants with sarcomatous features [65]. The other three groups tend to occur in bones and are also usually benign. In about $70 \%$ of the cases studied, FGF-23 is positive, and the proliferating cells within the tumor are usually the source of FGF-23 [64]. In several cases of TIO tumors, somatostatin receptors were described [66].

\section{Clinical expression}

Clinical manifestations are generally non-specific and often progressive, including muscle and bone pain, which is usually the first presentation, prominent proximal muscle weakness, osteomalacia/rickets, sometimes height and weight loss, and high risk of fractures (especially in the ribs, vertebral bodies, and femoral neck) [38]. Clinically, it most commonly occurs in young-adult subjects. The diagnosis is usually delayed for years (about 5), due to the non-specific nature of the presenting symptoms, failure to evaluate hypophosphatemia, and difficulty in localizing the responsible tumor [38]. The clinical suspicion of TIO should be set for any patient with osteomalacia for which there is not obvious cause or familial history.

\section{Biochemical expression}

Laboratory exams should evaluate renal phosphate wasting with decreased Tmp/GFR, fasting hypophosphatemia, inappropriate (normal or low) $1,25(\mathrm{OH})_{2} \mathrm{D}_{3}$ concentrations, normal serum calcium, PTH, and 25- hydroxyvitamin D $[25(\mathrm{OH}) \mathrm{D}]$ levels. Numerous reports show elevation of FGF23 in some but not all patients with TIO. In some cases, PTH can be high, reflecting secondary hyperparathyroidism, which may be in part due to low $1,25(\mathrm{OH})_{2} \mathrm{D}_{3}$ caused by elevated FGF-23 levels. In 5\% of patients with TIO, tertiary hyperparathyroidism can occur [67]. Moreover, levels of ALP are usually elevated because of osteoblastic hyperactivity and active bone remodeling in the context of active osteomalacia [38].

\section{Diagnosis}

The diagnosis of TIO can be challenging because the tumors are often small and difficult to find. It is important to scan the whole body, including extremities, which is often excluded in routine nuclear medicine imaging, as tumors can occur anywhere in the body. It is difficult to identify the tumor associated with TIO, and several instrumental exams have been employed in an effort to localize the tumor. Octreotide scanning is commonly performed with 111 In-labeled pentatreotide. Octreotide scintigraphy is successfully used to locate tumors in up to $95 \%$ of patients with TIO [38]. Fluorodeoxyglucose (18FFDG) PET/CT and gallium (68Ga) DOTATATE PET/CT have also been used successfully in identifying candidate tumors. Other localizing studies that have been used include total body magnetic resonance imaging, computed tomography, and selective venous sampling for FGF-23 [38]. Finally, single-photon emission tomography (SPECT) or hybrid SPECT/CT enables three-dimensional imaging and better tumor contrast but usually is limited to areas of suspected abnormality rather than a whole body survey [38]. Total body magnetic resonance imaging and computed tomography should be used to confirm the site of the tumor after identification by functional imaging [38]. In some cases, the tumor is occult and difficult to locate, or the tumor may take several years to manifest clinically. In case of tumor location failure, imaging exams should be repeated every $1-$ 2 years [38]. 
TIO should be included in the differential diagnosis in patients with progressive weakness, bone and muscle pain, and multiple fractures. However, in many cases, TIO is misdiagnosed with other musculoskeletal, rheumatologic diseases, or even psychiatric diseases. Differential diagnosis should also include renal Fanconi's syndrome, a disease of the proximal renal tubules, characterized by impaired phosphate reabsorption and low levels of phosphatemia and additionally amino aciduria, glycosuria, and low serum bicarbonate that are not present in FGF-23-mediated hypophosphatemia [38].

Removal of the responsible tumor leads to reversal of typical TIO features, and the diagnosis is confirmed by the dramatic improvement of symptoms and correction of metabolic abnormalities following its complete excision. Measurement of serum levels of FGF-23 should be performed to confirm the diagnosis. Confirmation of disease causing mutation within phosphatonin genes may also be performed. Bone histomorphometric analysis can confirm the excess osteoid of bone tissue [38].

\section{Differential diagnosis of renal phosphate wasting disorders}

In case of suspicion of renal phosphate wasting diseases, the first step must be to determine whether urinary phosphate excretion is appropriate, followed by careful medical history and objective examination to help distinguish the various forms.

Indices of phosphate excretion, such as tubular maximal reabsorption of phosphate, adjusted for glomerular filtration rate (TmP/GFR), allow us to determine if renal loss is or is not a factor in causing hypophosphatemic state. Paired morning fasting serum and 2-h urinary creatinine and phosphate levels while the patient is off phosphate therapy for at least $24 \mathrm{~h}$ are required. The tubular reabsorption of phoshate (TRP) can be used to calculate TmP/GFR: TRP $=1-$ (fractional excretion of phosphate $)=1-([$ Urine phosphate $] /$ [plasma phosphate $] \times$ [plasma creatinine] / [urine creatinine]). In case of TRP $\leq$ 0.86 , phosphate reabsorption is maximal and there is a linear relationship between plasma phosphate concentration and excretion, and TmP/GFR is calculated as follows: TmP/GFR = $\mathrm{TRP} \times$ [plasma phosphate]. In case of TRP $>0.86, \mathrm{TmP} / \mathrm{GFR}$ is defined as follows: TmP/GFR $=0: 3 \times$ TRP / $\{1-(0: 8 \times$ TRP) $\} \times$ [plasma phosphate] [1]. Another method to measure $\mathrm{TmP} / \mathrm{GFR}$ is the use of a nomogram after measuring fasting plasma and urine phosphate and creatinine concentrations [68]. Like serum phosphate, TmP/GFR is higher in young children than adults [1].

Regarding biochemical expression of the genetic phosphate wasting disorders and TIO, Table 1, as already described, summarizes the typical laboratory test alterations.
A low serum $1,25(\mathrm{OH})_{2} \mathrm{D}_{3}$ concentration in a patient without advanced CKD (stages 4 to 5 ) and with an adequate $25(\mathrm{OH}) \mathrm{D}$ level signal the possibility of a hypophosphatemia due to excess FGF-23 levels. The measurement of FGF-23 may be helpful, but this test is not available widely, as already described. It is important to remember that sample type, rapid sample centrifugation and freezing, and choice of assay are factors that affect FGF-23 levels. Moreover, in patients with XLH, plasma FGF-23 concentrations are elevated but are quite variable [69]. During hypophosphatemia, iFGF-23 concentration greater than the normal population mean, which according to the assays used is approximately $30 \mathrm{pg} / \mathrm{ml}$, should be considered inappropriately elevated and likely causative of the hypophosphatemia [69, 70]. However, an elevated FGF-23 concentration is not specific for XLH, even in the setting of hypophosphatemia, since ADHR, ARHR, TIO, and FD cause FGF-23-mediated hypophosphatemia. Nevertheless, a low FGF-23 concentration in the setting of hypophosphatemia suggests a different cause, such as Fanconi syndrome, dietary phosphate deficiency, or malabsorption $[69,70]$.

Lastly, an accurate pathological and pharmacological medical history allows to exclude other acquired causes of renal wasting disorders in the differential diagnosis.

\section{Treatments for phosphate wasting disorders}

\section{Therapy for XLH}

\section{Current standard of care and monitoring}

Current standard treatment of phosphate wasting genetic disorders is based on treatment of the XLH, due to similarities in pathophysiology between the pathologies. However, most of the published studies treating XLH are uncontrolled or use only historical controls, and there is a lack of specific studies on the less common diseases [62]. The most commonly prescribed medical therapy consists of calcitriol or 1 alfacalcidol and phosphate supplementation, especially for children, from the time of diagnosis until growth is complete. Subsequently, in adulthood, the need for treatment must be carefully evaluated, balancing potential benefits with known risks such as nephrocalcinosis and hyperparathyroidism, and the treatment requires ongoing monitoring. Currently, there is no consensus regarding indications of the treatment in adult subjects affected by XLH and overall by hypophosphatemic rickets. Many adult patients do not have clinical manifestations without treatment, while others can develop bone pain and pseudofractures [62].

It is mostly accepted that treatment should be maintained or reinitiated in all patients in case of pain, which may be caused by bone microfractures and/or osteomalacia [41, 49]. In case of planed surgical interventions, such as corrective osteotomy, 
or dental implants, the patients should be treated at least for a period to promote bone mineralization [41, 49]. Moreover, adult patients could be treated with pharmacological approach in case of spontaneous insufficiency fractures, which may heal faster with therapy. In case of orthopedic procedures, the treatment could reduce recovery time and the risk of prosthetic loosening in patients undergoing joint replacement, with high serum ALP activity, osteomalacia, and bone pain [41]. Enthesopathy, in adult patients, does not seem to improve with current medical therapy, and risk factors associated with its occurrence are unknown [41, 47]. In case of pain and joint stiffness, appropriate rehabilitation should be associated to pharmacological management [49].

In asymptomatic adult patients, the treatment with phosphate and vitamin D analogs is debatable, due to the absence of clear evidence for positive clinical benefits and the possible side effects. On the other hand, long-term consequences of chronic low serum phosphate levels in adult subjects are not known [49]. A chronic reduced $1,25(\mathrm{OH})_{2} \mathrm{D}_{3}$ synthesis may have an important clinical role, considering its beneficial effects on metabolism, cardiovascular and immune systems, and tumor prevention [49].

In case of increased demands on phosphate and calcium, such as pregnancy, the pharmacological treatment could be administered, in order to ensure sufficient mineralization of the fetal skeleton, or in case of lactation, in order to allow an adequate galactopoiesis, and prevent worsening of the phosphate deficit in the mother in both these physiological situations. However, so far, there are not studies that prove it [49].

The current goal of treatment of XLH in adult patients is not necessarily and specifically to normalize the serum phosphate levels but rather to improve the symptoms, osteomalacia, accelerate fracture healing, and decrease the number of necessary surgeries. Although the treatment reduces symptoms, hyperphosphaturia persists, since the treatment does not alter the impaired tubular phosphate reabsorption [41, 49].

The conventional treatment in adult patients is based on oral phosphate salts, usually given two to four times/day, and active vitamin D metabolites. Most XLH treatment studies do not consistently report weight-based dosing of calcitriol and phosphate, and the reported doses vary widely (phosphate supplements $=0-2000 \mathrm{mg} /$ day, two to four times/day; vitamin $\mathrm{D}$ analogs, alfacalcidol $=0-1.5 \mathrm{mcg} / \mathrm{day}$, equivalent dose in calcitriol was obtained divided by a factor 2, once or twice/ day) $[32,41,49]$. Frequent dosing is useful to avoid a rapid decline of the available drug and to reduce volatility in serum phosphate levels. Moreover, the use of liquid formulations may improve adherence to therapy and allow more precise dosing.

Treatment with these two agents should be carefully monitored to guarantee an adequate balance. Gradual titration up to target doses of oral phosphate salts is advised, since high doses can cause gastrointestinal side effects, such as abdominal pain or diarrhea. Small doses are usually prescribed and subsequently titrated toward targets to minimize gastrointestinal symptoms. Some patients may need smaller doses based on their weight, whereas others may require doses mildly above these ranges [41].

The use of monotherapy with only phosphate salts is not appropriate and is ineffective. Oral phosphate monotherapy does not adequately improve osteomalacia, and it is associated with a relevant risk of iatrogenic hyperparathyroidism. Phosphate supplementation alone increases serum phosphate, decreases ionized calcium, and consequently increases PTH levels. On the other hand, the association of active analogs of vitamin D and oral phosphate significantly improves the osteomalacia, and activated vitamin D has a suppressive effect on PTH, given that it increases gastrointestinal calcium and phosphate absorption [71].

The major risks of long-term therapy with calcitriol and phosphorus in adult subjects with XLH are similar to those in children, such as hypercalcemia and hypercalciuria [41]. Special attention should be given to potentially severe side effects such as nephrocalcinosis, leading in some cases to CKD. This renal complication is probably due to the high throughput of calcium and phosphate induced by pharmacological treatment, causing hypercalciuria, and simultaneously continuous renal losses. Moreover, treatment with phosphate can cause secondary and tertiary hyperparathyroidism. Despite the described benefits of this pharmacological treatment, it tends to increase FGF-23 in both the Hyp mouse and humans with XLH $[62,73]$, but the clinical consequences of this rise in FGF-23 are uncertain. A cross-sectional analysis of a small number of treated patients showed that FGF-23 concentrations did not correlate with indices of disease severity [70]. However, high FGF-23 levels may have deleterious effects on the health of these subjects, of note on metabolism and cardiac functions [49].

Careful laboratory monitoring is essential to minimize the risks associated to pharmacological treatment. Laboratory monitoring, including serum calcium, phosphorus, creatinine, bone alkaline phosphatases and PTH, and 24-h urinary excretion of calcium or a fasting spot urinary calcium/ creatinine ratio, is recommended every 3-4 months during the first year of treatment, or if there are dosing changes or changes in the patient calcium intake through diet and/or supplementation, in order to avoid complications, such as hypercalcemia, hypercalciuria, or hyperparathyroidism [41, 49]. After the first year, treated adult patients should be monitored every 6-12 months. In case of hypercalcemia or hypercalciuria, the calcitriol dose must be reduced [41]. Serum ALP activity is the most useful biomarker for drug effects on bone response, serving as a surrogate marker for bone healing. During the first few months of therapy, serum ALP activity may transiently rise and during the initial healing phase of the osteomalacia. To prevent secondary hyperparathyroidism, PTH levels are 
commonly measured, and in case of increasing PTH levels, the calcitriol dose can be increased, or the phosphate dose can be reduced. The optimal amounts of these two drugs are determined by monitoring serum and urine calcium [41].

Renal ultrasonography can be performed at 2- to 5-year intervals to detect moderate to severe, or progressive, nephrocalcinosis. Radiography and computed tomography are not recommended for monitoring, and unnecessary radiation exposure should be avoided [41]. Moreover, technetium bone scans may be useful in case of suspected stress fractures [41].

Finally, clinical monitoring should provide an annual assessment of weight control, mobility, pain, and any dental problems. In case of pregnancy, the clinical monitoring will be every 3 months [49].

\section{GH treatment}

Treatment with recombinant human growth hormone (GH) was shown to improve growth velocity and thus standardized height without aggravating preexisting body disproportion in short children with XLH despite regular treatment with active vitamin D and phosphate [73-76]. However, it remains to be proven if this treatment is able to increase adult height in short children with XLH, since adequately powered studies on this topic are lacking [77]. Therefore, outweighing the potential benefits, costs, and side effects, it is not recommended as a routine treatment for this disease $[32,75]$.

\section{Treatments of dental and hearing complications}

Dental complications, especially root abscess, are an important problem in adult patients with XLH. Defective dentin and microdefects in the enamel increase microorganism access to the pulp chamber, resulting in abscess formation. These patients are subjected to numerous root canals and tooth extractions [62]. Therefore, consistent dental hygiene, including brushing two to three times a day and regular dental hygienist visits, is recommended. No specific therapy has been clearly demonstrated to prevent this complication. The role of sealant application on the incidence of root abscesses is currently being studied [41, 62]. Future investigations will have to determine the possible benefit of treatment with vitamin D analogs and phosphate supplements on the periodontal status [49].

Regarding hearing impairments in patients with XLH, currently, it is not known whether phosphate supplements and vitamin D analogs can modify the hearing evolution [49].

\section{Surgical treatments}

Surgical approach is usually indicated for the treatment of severe bowing, tibial torsion, or pathological fractures unlikely to improve with medical management. Prophylactic surgery is indicated to reduce future fracture risk and/or improve lower limb alignment. Osteotomy with plating, multiple osteotomies, and intramedullary fixation are standard methods for surgical management [78].

It has been described that the healing time after orthopedic surgery in untreated patients varies between 6 months and 1 year, whereas pharmacological treatment can shorten it [41]. Moreover, it has been described that the treatment appears to reduce the risk of prosthetic joint loosening, so it is recommended to begin therapy in untreated patients $3-$ 6 months before the operation and continue for 6-9 months afterwards [41].

\section{Future treatments for XLH}

After the identification of FGF-23 as a humoral mediator of phosphate wasting in XLH disease, and further discoveries regarding its pathophysiology, much effort has been directed toward newer pharmacological strategies that target the FGF23 pathway. In addition to this, several novel treatments are being studied, including methods to modulate PTH levels, modulate the downstream consequences of high FGF-23 concentrations, alter FGF-23 production or degradation, and block the negative effects of FGF-23. In the future, another interesting pharmacological target could directly modulate the activity of the renal sodium-phosphate cotransporters, on which FGF-23 acts [62].

\section{Calcimimetics and thiazide diuretics or amiloride in XLH}

Cinacalcet is a calcimimetic that has recently been approved for the treatment of secondary hyperparathyroidism in endstage renal disease and for the treatment of primary hyperparathyroidism due to parathyroid adenoma, carcinoma, or hyperplasia, not operable surgically. It is an allosteric modulator of the calcium-sensing receptor $(\mathrm{CaR})$, with a suppressive effect on PTH secretion, the tubular reabsorption of calcium, and the serum calcium concentration in patients with hyperparathyroidism. In addition, it may indirectly reduce FGF-23 concentrations [79].

During the standard treatment with calcitriol and phosphate supplementation for several years in for XLH patients, cinacalcet could be used to normalize PTH values in case of significant and persistent secondary or tertiary hyperparathyroidism, especially if accompanied by rising serum ALP levels. Initial doses of $30 \mathrm{mg}$ at bedtime can be increased to $60 \mathrm{mg}$, but the data regarding the therapeutic response described in the literature are scarce and variable [41, 80]. A study conducted on eight patients with the diagnosis of XLH showed that single doses of cinacalcet plus an oral phosphate dose increased serum phosphate and TmP/GFR compared to phosphate alone in XLH, while suppressing PTH compared to phosphate plus calcitriol [81]. Moreover, a case report 
described that the addition of cinacalcet reduced PTH and calcium levels and increased serum phosphate, as was expected, but also reduced FGF-23 levels, which remained stable after 6 months of therapy [82]. However, in a recent study in Hyp mice an orthogous animal model of XLH, monotherapy with cinacalcet (R568) reduced PTH and FGF-23 synthesis in bone but failed to restore vitamin $\mathrm{D}$ and phosphate metabolism and skeletal abnormalities [83]. Therefore, long-term clinical trials should be conducted in order to investigate cinacalcet's potential as an adjuvant treatment of XLH [62].

\section{Calcitonin}

Calcitonin also stimulates $1,25(\mathrm{OH})_{2} \mathrm{D}_{3}$ production in patients with XLH, and its administration was shown to lower FGF-23 concentrations for several hours after a single dose [85]. Moreover, there was an increase in serum phosphorus and $1,25(\mathrm{OH})_{2} \mathrm{D}_{3}$ following calcitonin administration, without a significant change in the TmP/GFR [84]. Since osteocytes are the primary source of FGF-23, these findings imply that the decline in FGF-23 levels observed in patients with XLH was likely due to the direct effect of calcitonin on osteocytes [84].

However, the use of calcitonin is much debated. In 2012, the European Medicines Agency (EMA) carried out a review regarding the benefits/risks associated to the use of calcitonin, concluding that there was evidence of a small increased risk of cancer with its long-term use. The Agency's Committee for Medicinal Products for Human Use recommended that calcitonin-containing medicines should only be authorized for short-term use in Paget's disease, acute bone loss caused by immobilization, and hypercalcemia due to cancer. Moreover, the committee concluded that the benefits of calcitonin did not outweigh their risks for the osteoporosis therapy and, therefore, that they should no longer be used for this disease. After a reexamination, the committee confirmed its recommendation also in 2012 [85]. On the other hand, there are some calcitonin salmon products approved by the Food and Drug Association (FDA) to treat postmenopausal osteoporosis, since, so far, the FDA's review of these products found there is no conclusive evidence of a causal relationship between the use of these products and cancer risk. The FDA will continue to reevaluate this issue as more information becomes available, and currently, these products represent an option for those patients who cannot or do not want to use other treatments for osteoporosis. The FDA recommends that healthcare professionals continue to assess each patient's benefits and risks of all available treatments [86].

\section{Hexa-D-arginine}

Another pharmacological approach for the inhibition of the FGF-23 pathway could be a C-terminal fragment of FGF-23, which in studies conducted in Hyp mice has been shown to successfully increase serum phosphate and $1,25(\mathrm{OH})_{2} \mathrm{D}_{3}$ levels [62].

Hexa-D-arginine (D6R) is a small peptide that stimulates 7B2 mRNA expression, enhances 7B2-SPC2 activity, and decreases FGF-23 mRNA [62]. So far, preliminary data have shown that hexa-arginine upregulates the subtilisin convertase system, degrading FGF-23 [62]. It suggests that this agent could be used to reduce circulating intact FGF-23 levels in patients with XLH [62].

\section{FGF23 neutralizing antibodies}

With recent discoveries, much effort has been directed toward new strategies that specifically target the FGF-23 pathway. Indeed, recent studies have been conducted and focused on the use of anti-FGF-23 antibodies (KRN23) as a possible treatment for patients with XLH.

KRN23 is a recombinant fully human IgG1 monoclonal antibody, developed to treat XLH by binding to FGF-23 and inhibiting its activity, to restore a normal phosphate homeostasis [87]. KRN23 is expressed in Chinese hamster ovary dihydrofolate reductase-deficient cells. This new agent binds the amino-terminal domain of FGF-23 that interacts with the FGF-binding portion of the combination FGFR1/Klotho receptor, preventing FGF-23 from binding to and signaling from its receptor. Both intact and fragmented FGF-23 polypeptides are immunoprecipitated with KRN23. Therefore, KRN23 restores tubular reabsorption of phosphate (TmP/GFR) from the kidney and increases the production of $1,25(\mathrm{OH})_{2} \mathrm{D}_{3}$. This dual action should improve serum phosphorus concentration, which is expected to improve bone mineralization and reduce the diverse bone and non-bone manifestations in XLH [87].

Regarding non-clinical studies in the Hyp mouse, the use of KRN23 resulted in inhibition of endogenous FGF-23 activity and in increase of circulating phosphate and $1,25(\mathrm{OH})_{2} \mathrm{D}_{3}$ levels [87]. In short- and long-term treatment studies, a reduction of phosphaturia and improvement of phosphatemia and $1,25(\mathrm{OH})_{2} \mathrm{D}_{3}$ levels have been observed [88]. After 4 weeks of treatment, decreased unmineralized osteoid thickness, improved growth, decreased growth plate thickness, and partial correction of the osteomalacia were reported. In addition, the length and shape of the Hyp mouse femur improved during treatment with FGF-23 neutralizing antibodies [88]. These antibodies also improved muscle weakness as demonstrated by the improvement of spontaneous motor activity and grip strength in Hyp mice [88].

A similar antibody to human FGF-23 is currently under investigation in clinical trials as a potential therapeutic agent for XLH in humans [89-91]. In adult patients with XLH, three clinical studies have been conducted, including a single dose phase 1 safety and tolerability study of KRN23 (KRN23-US02 ), a repeat-dose phase $1 / 2$ dose escalation study (KRN23INT-002), and an associated treatment extension study 
(KRN23-INT-002). A phase 2 dose-finding, pharmacodynamic, and safety study is also being conducted in pediatric XLH patients (UX023-CL201).

In the phase 1 study, KRN23 increased TmP/GFR, serum phosphorous, and $1,25(\mathrm{OH})_{2} \mathrm{D}_{3}$ levels, and patients had no increased risk of nephrocalcinosis, hypercalciuria, hypercalcemia, anti-KRN23 antibodies, or elevated serum PTH or creatinine levels. The half-life of KRN23 after subcutaneous dosing was 13-19 days, and serum phosphorus remained higher than baseline beyond 4 weeks, supporting dosing every 4 weeks [92, 93].

Subsequently, a multicenter phase $1 / 2$ open-label, dose escalation study was conducted to evaluate the safety and efficacy of subcutaneous KRN23 administered every 28 days for four doses, followed by a 12-month extension study, in order to test the hypothesis that monthly KRN23 would safely improve serum phosphorus in adult patients affected by XLH [96]. Repeated doses of KRN23, up to $1.0 \mathrm{mg} / \mathrm{kg}$, were well tolerated by adult subjects throughout the phase $1 / 2$ dose escalation and associated treatment extension study. In all patients, monthly KRN23 significantly increased serum phosphorus, TmP/GFR, and $1,25(\mathrm{OH})_{2} \mathrm{D}_{3}$ levels [94]. Throughout the study, adverse events were reported in 27 of the 28 subjects and 18 subjects $(64 \%)$ had adverse events considered drug-related, such as diarrhea and arthralgia and injection site reactions. Six grade 3 adverse events occurred, once each among five subjects (myalgia, extremity pain, cervical spine stenosis, breast cancer, hypertensive crisis, all unrelated to study drug, and restless leg syndrome, related to study drug). No deaths were described. Overall, anti-KRN23 antibodies were not detected in any subject, and no patterns of dose-limiting toxicity have been associated with KRN23 treatment [94].

Therefore, single and repeat-dose clinical studies show that subcutaneous administration of KRN23 consistently increased and sustained serum phosphorus levels and TmP/ GFR, without major alterations of vitamin D metabolism or urine calcium levels. The data derived from the long-term extension study shows that KRN23 could provide sustained increases in serum phosphorus levels and improve bone physiology, structure, and function [94]. Currently, a randomized, double-blind, placebo-controlled, phase 3 study to assess the efficacy and safety of KRN23 in adults with XLH is ongoing (UX023-CL303).

Finally, a recent study (phase $1 / 2$, open-label, multicenter, dose escalation trial) has been conducted to validate the use of SF-36v2 Health Survey (SF-36v2) and the Western Ontario and McMaster Osteoarthritis Index (WOMAC) in order to measure the health-related quality of life (HRQoL) in 28 adult patients with XLH and determine the change in HRQoL before and after treatment with KRN23. The drug was administered subcutaneously up to four doses every 28 days. The use of KRN23 was associated with significantly improved patient perception of their physical functioning and stiffness related to their disease. This investigation showed that the SF-36v2 and WOMAC could be valid tools for assessing HRQoL in these patients and in the future could provide a valuable addition to other criteria in evaluating new treatment options in adult subjects affected by XLH [95].

\section{Current standard of care of TIO}

The gold standard treatment for TIO is the surgical resection of tumor with a wide margin, to avoid recurrences [96]. After tumor removal, within days to weeks, FGF-23 disappears rapidly from the blood circulation, renal phosphate wasting decreases, $1,25(\mathrm{OH})_{2} \mathrm{D}_{3}$ concentration increases, and serum phosphate levels return to normal by day 5 after operation $[38,97]$. Bone healing starts immediately, but, depending on the severity of the disease, it may take a short time or more than a year for a significant clinical improvement. Most patients feel better within days to weeks of tumor removal [38].

In case of incompletely resected tumors, post-operative radiotherapy for margin positive tumors used to avoid recurrence or metastasis has been described, but data are still limited $[67,96]$. Subsequent radiotherapy can be used to avoid recurrence or, rarely, metastases, in less than $5 \%$ of the patients with TIO $[64,67]$. The course after metastasis is quite variable, and survival of up to 30 years has been reported [98]. So far, there is no chemotherapy with demonstrated efficacy in treating metastatic TIO.

In case the tumor is not localizable or is not surgically resectable, medical treatment with phosphate supplementation and calcitriol or alfacalcidiol is usually used, as in XLH (see previous section).

Image-guided ablation with radiofrequency or cryoablation is a promising alternative for these patients [99]. Although surgery remains the treatment of choice, image-guided ablation may be an effective, less invasive, and safe treatment for patients with inoperable TIO [99]. However, long-term efficacy of these modalities has not been demonstrated.

Octreotide is an alternative medical therapy that may be used, but not all patients respond to this treatment, possibly due to inter-individual differences in tumor somatostatin receptor expression [66].

Treatment with cinacalcet could also be effective for the treatment of TIO patients to decrease phosphaturia, reduce the need for phosphate and calcitriol supplements, and bring about bone healing [100]. In two TIO patients, cinacalcet improved long-term phosphate concentrations while the doses of calcitriol and phosphate were decreased [100]. In addition, calcitonin was used in a patient with TIO, decreasing serum FGF-23 levels [101]. However, further studies are needed.

Finally, preliminary evidence shows that KRN23 treatment increases serum phosphate and $1,25(\mathrm{OH})_{2} \mathrm{D}_{3}$ levels, also in patients affected by TIO [102]. These findings show that 
KRN23 will potentially be an effective treatment in cases that cannot be cured easily with surgery $[96,103]$.

\section{Current care of hereditary hypophosphatemic rickets with hypercalciuria}

Due to preexisting hypercalciuria, patients with HHRH must not be treated with vitamin $\mathrm{D}$ in order to prevent severe nephrocalcinosis and should receive only phosphate supplementation. Phosphate dosage based on elemental phosphorus is usually in the range of $1-2.5 \mathrm{~g}$, given in four to five divided doses daily in adults and older children $(20-50 \mathrm{mg} / \mathrm{kg}$ of elemental phosphorus per day). The aim is to decrease the high $1,25(\mathrm{OH})_{2} \mathrm{D}_{3}$ levels in order to reduce intestinal calcium absorption and to increase the phosphate supply, enhancing and maintaining bone mineralization. Moreover, avoidance of a high sodium diet is recommended [30].

\section{Current care of fibrous dysplasia and McCune-Albright syndrome}

The therapeutic management of hypophosphatemia is the same as in other FGF23-mediated phosphate wasting diseases, including the use of phosphate and active vitamin D [104]. So far, there are no controlled studies to support that treating hypophosphatemia improves bone pain or decreases bone fractures; however, observations of treated patients affected by FD/MAS suggest that this treatment may improve outcomes [104].

\section{Conclusions}

Knowledge concerning mechanisms and processes involved in phosphate wasting disorders has greatly increased in the last decade, especially by the demonstration of the central role of the factor FGF-23 derived by bone.

Pharmacological management requires an adequate balance between the benefits derived from treatment itself with complicated and long-term monitoring and the potential risks, and these differ over the lifetime. Involving clinicians with experience in treating these disorders is considered fundamental to the successful management of these patients. Currently, pharmacological conventional treatment of these disorders offers limited efficacy and is potentially associated to gastrointestinal, renal, and parathyroid complications, compromising the patient's quality of life.

Attempts to modify FGF-23 activity are certainly a fundamental point in the treatment of these diseases, also because, as already described, FGF-23 has several extraskeletal actions. Recent studies and trials have shown that FGF-23 blockade through neutralizing antibodies offers a new possible treatment for patients affected by XLH and may open new therapeutic choices for other FGF-23-related disorders of renal phosphate wasting and bone mineralization defects. Moreover, long-term studies on the use of drugs that reduce FGF-23 levels could clarify whether some clinical complications, such as enthesopathy and dental abscesses, are mediated in part by FGF-23 itself or by low phosphorus levels or other factors.

In the future, other agents able to decrease FGF-23 expression or its activity, or modulate renal transporters, may open the way for other successful and effective therapeutic alternatives for these disorders. These pharmacological efforts may lead to greater clinical efficacy, reduction of side effects, and improvement in terms of quality of life for these patients.

Acknowledgements MKJ is supported by the National Institute of Health Research Oxford Biomedical Research Centre. The views expressed are those of the author and not necessarily those of the NHS, the NIHR, or the Department of Health. This work was supported by Fondazione Italiana Ricerca Malattie Ossee (F.I.R.M.O.) Fondazione Raffaella Becagli.

\section{Compliance with ethical standards}

Conflicts of interest MKJ is a member of the Kyowa Kirin Hakin Advisory Board and has received honoraria and research grants from Kyowa Kirin Hakin. MLB is a consultant for Alexion, Bruno Farmaceutici, Shire, Servier, and Kyowa Kirin and received academic grants and/or speaker fees from Abiogen, Alexion, Amgen, Bruno Farmaceutici, Eli Lilly, Kyowa Kirin, MSD, NPS, Servier, Shire, and SPA. She has received honoraria from Amgen, Bruno Farmaceutici, and Kyowa Kirin. The other authors declare that they have no conflict of interest or disclosures.

Human and animal rights For this type of study, formal consent is not required.

\section{References}

1. Manghat P, Sodi R, Swaminathan R (2014) Phosphate homeostasis and disorders. Ann Clin Biochem 51:631-656

2. Demay MB, Sabbagh Y, Carpenter TO (2007) Calcium and vitamin D: what is known about the effects on growing bone. Pediatrics 119:141-144

3. Fukumoto S (2014) Phosphate metabolism and vitamin D. Bonekey Rep 3:497-502

4. Pavone V, Testa G, Gioitta Iachino S, Evola FR, Avondo S, Sessa G (2015) Hypophosphatemic rickets: etiology, clinical features and treatment. Eur J Orthop Surg Traumatol 25:221-226

5. Segawa H, Kaneko I, Yamanaka S, Ito M, Kuwahata M, Inoue Y, Kato S, Miyamoto KI (2004) Intestinal Na-P(i) cotransporter adaptation to dietary $\mathrm{P}(\mathrm{i})$ content in vitamin $\mathrm{D}$ receptor null mice. Am J Physiol Renal Physiol 287:F39-F47

6. Rizzoli R, Fleisch H, Bonjour JP (1977) Role of 1,25dihydroxyvitamin D3 on intestinal phosphate absorption in rats with a normal vitamin D supply. J Clin Invest 60:639-647

7. Capuano P, Radanovic T, Wagner CA, Bacic D, Kato S, Uchiyama Y, St.-Arnoud R, Murer H, Biber J (2005) Intestinal and renal adaptation to a low-Pi diet of type II NaPi cotransporters in vitamin D receptor- and 1alpha OHase-deficient mice. Am J Physiol Cell Physiol 288:C429-C434 
8. Mulroney SE, Woda CB, Halaihel N, Louie B, McDonnell K, Schulkin J, Haramati A, Levi M (2004) Central control of renal sodium-phosphate (NaPi-2) transporters. Am J Physiol Renal Physiol 286:F647-F652

9. Andrukhova O, Zeitz U, Goetz R, Mohammadi M, Lanske B, Erben RG (2012) FGF23 acts directly on renal proximal tubules to induce phosphaturia through activation of the ERK1/2-SGK1 signaling pathway. Bone 51:621-628

10. Prie D, Urena Torres P, Friedlander G (2009) Latest findings in phosphate homeostasis. Kidney Int 75:882-889

11. Haussler MR, Whitfield GK, Kaneko I, Haussler CA, Hsieh D, Hsieh JC, Jurutka PW (2013) Molecular mechanisms of vitamin D action. Calcif Tissue Int 92:77-98

12. Delanaye P, Krzesinski JM, Warling X, Moonen M, Smelten N, Médart L, Bruyère O, Reginster JY, Pottel H, Cavalier E (2014) Clinical and biological determinants of sclerostin plasma concentration in hemodialysis patients. Nephron Clin Pract 128:127-134

13. Fukumoto S, Martin TJ (2009) Bone as an endocrine organ. Trends Endocrinol Metab 20:230-236

14. Yamashita T, Yoshioka M, Itoh N (2000) Identification of a novel fibroblast growth factor, FGF-23, preferentially expressed in the ventrolateral thalamic nucleus of the brain. Biochem Biophys Res Commun 277:494-498

15. Ubaidus S, Li M, Sultana S, de Freitas PH, Oda K, Maeda T, Takagi R, Amizuka N (2009) FGF23 is mainly synthesized by osteocytes in the regularly distributed osteocytic lacunar canalicular system established after physiological bone remodeling. J Electron Microsc 58:381-392

16. Masi L, Beltrami G, Ottanelli S, Franceschelli F, Gozzini A, Zonefrati R, Galli G, Ciuffi S, Mavilia C, Giusti F, Marcucci G, Cioppi F, Colli E, Fossi C, Franchi A, Casentini C, Capanna R, Brandi ML (2015) Human preosteoblastic cell culture from a patient with severe tumoral calcinosis-hyperphosphatemia due to a new GALNT3 gene mutation: study of in vitro mineralization. Calcif Tissue Int 96:438-452

17. Masi L, Gozzini A, Franchi A, Campanacci D, Amedei A, Falchetti A, Franceschelli F, Marcucci G, Tanini A, Capanna R, Brandi ML (2009) A novel recessive mutation of fibroblast growth factor-23 in tumoral calcinosis. J Bone Joint Surg Am 91:1190-1198

18. Martin A, David V, Quarles LD (2012) Regulation and function of the FGF23/Klotho endocrine pathways. Physiol Rev 92:131-155

19. Goetz R, Nakada Y, Hu MC, Kurosu H et al (2010) Isolated Cterminal tail of FGF23 alleviates hypophosphatemia by inhibiting FGF23-FGFR-Klotho complex formation. Proc Natl Acad Sci U S A $107: 407-412$

20. Kurosu H, Ogawa Y, Miyoshi M, Yamamoto M, Nandi A, Rosenblatt KP, Baum MG, Schiavi S, Hu MC, Moe OW, Kuroo M (2006) Regulation of fibroblast growth factor-23 signaling by klotho. J Biol Chem 281(10):6120-6123

21. Ferrari SL, Bonjour JP, Rizzoli R (2005) Fibroblast growth factor23 relationship to dietary phosphate and renal phosphate handling in healthy young men. J Clin Endocrinol Metab 90:1519-1524

22. Collins MT, Lindsay JR, Jain A, Kelly MH, Cutler CM, Weinstein LS, Liu J, Fedarko NS, Winer KK (2005) Fibroblast growth factor-23 is regulated by 1 alpha,25-dihydroxyvitamin $\mathrm{D}$. J Bone Miner Res 20:1944-1950

23. Antoniucci DM, Yamashita T, Portale AA (2006) Dietary phosphorus regulates serum fibroblast growth factor-23 concentrations in healthy men. J Clin Endocrinol Metab 91:3144-3149

24. Kawai M, Kinoshita S, Shimba S, Ozono K, Michigami T (2014) Sympathetic activation induces skeletal Fgf23 expression in a circadian rhythm-dependent manner. J Biol Chem 289:1457-1466

25. Carpenter TO, Insogna KL, Zhang JH, Ellis B, Nieman S, Simpson C et al (2010) Circulating levels of soluble klotho and FGF23 in X-linked hypophosphatemia: circadian variance, effects of treatment, and relationship to parathyroid status. J Clin Endocrinol Metab 95:E352-E357

26. Kawata T, Imanishi Y, Kobayashi K, Miki T, Arnold A, Inaba M, Nishizawa Y (2007) Parathyroid hormone regulates fibroblast growth factor-23 in a mouse model of primary hyperparathyroidism. J Am Soc Nephrol 18:2683-2688

27. Lavi-Moshayoff V, Wasserman G, Meir T, Silver J, NavehMany T (2010) PTH increases FGF23 gene expression and mediates the high-FGF23 levels of experimental kidney failure: a bone parathyroid feedback loop. Am J Physiol Renal Physiol 299:F882-F889

28. Tebben PJ, Singh RJ, Clarke BL, Kumar R (2004) Fibroblast growth factor 23, parathyroid hormone, and 1alpha,25dihydroxyvitamin D in surgically treated primary hyperparathyroidism. Mayo Clin Proc 79:1508-1513

29. Mace ML, Gravesen E, Nordholm A, Olgaard K, Lewin E (2018) Fibroblast growth factor (FGF) 23 regulates the plasma levels of parathyroid hormone in vivo through the FGF receptor in normocalcemia, but not in hypocalcemia. Calcif Tissue Int 102:85-92

30. Murali SK, Roschger P, Zeitz U, Klaushofer K, Andrukhova O, Erben RG (2016) FGF23 regulates bone mineralization in a 1, 25(OH) 2 D3 and Klotho-independent manner. J Bone Miner Res 31:129-142

31. Gattineni J, Baum M (2010) Regulation of phosphate transport by fibroblast growth factor 23 (FGF23): implications for disorders of phosphate metabolism. Pediatr Nephrol 25:591-601

32. Carpenter TO (2012) The expanding family of hypophosphatemic syndromes. J Bone Miner Metab 30:1-9

33. Lorenz-Depiereux B, Bastepe M, Benet-Pages A, Amyere M, Wagenstaller J, Muller-Barth U, Badenhoop K, Kaiser SM, Rittmaster RS, Shlossberg AH, Olivares JL, Loris C, Ramos FJ, Glorieux F, Vikkula M, Juppner H, Strom TM (2006) DMP1 mutations in autosomal recessive hypophosphatemia implicate a bone matrix protein in the regulation of phosphate homeostasis. Nat Genet 38:1248-1250

34. Martin A, David V, Laurence JS, Schwarz PM, Lafer EM, Hedge AM, Rowe PSN (2008) Degradation of MEPE, DMP1, and release of SIBLING ASARM-peptides (minhibins): ASARM-peptide(s) are directly responsible for defective mineralization in HYP. Endocrinology 149:1757-1772

35. Haffner D, Leifheit-Nestler M (2017) Extrarenal effects of FGF23. Pediatr Nephrol 32:753-765

36. Wolf M, Koch TA, Bregman DB (2013) Effects of iron deficiency anemia and its treatment on fibroblast growth factor 23 and phosphate homeostasis in women. J Bone Miner Res 28:1793-1803

37. Shimada T, Hasegawa H, Yamazaki Y, Muto T, Hino R, Takeuchi Y, Fujita T, Nakahara K, Fukumoto S, Yamashita T (2004) FGF23 is a potent regulator of vitamin D metabolism and phosphate homeostasis. J Bone Miner Res 19:429-435

38. Dadoniene J, Miglinas M, Miltiniene D, Vajauskas D, Seinin D, Butenas P, Kacergius T (2016) Tumour-induced osteomalacia: a literature review and a case report World J Surg Oncol 14

39. Donate-Correa J, Muros de Fuentes M, Mora-Fernández C, Navarro-González JF (2014) Pathophysiological implications of fibroblast growth factor-23 and Klotho and their potential role as clinical biomarkers. Clin Chem 60:933-940

40. Souberbielle JC, Prié D, Piketty ML, Rothenbuhler A, Delanaye P, Chanson P, Cavalier E (2017) Evaluation of a new fully automated assay for plasma intact FGF23. Calcif Tissue Int 101:510-518

41. Carpenter TO, Imel EA, Holm IA et al (2011) A clinician's guide to X-linked hypophosphatemia. J Bone Miner Res 26:1381-1388

42. Marcucci G, Cianferotti L, Beck-Peccoz P, Capezzone M, Cetani F, Colao A, Davì MV, degli Uberti E, Del Prato S, Elisei R, Faggiano A, Ferone D, Foresta C, Fugazzola L, Ghigo E, Giacchetti G, Giorgino F, Lenzi A, Malandrino P, Mannelli M, Marcocci C, Masi L, Pacini F, Opocher G, Radicioni A, 
Tonacchera M, Vigneri R, Zatelli MC, Brandi ML (2015) Rare diseases in clinical endocrinology: a taxonomic classification system. J Endocrinol Investig 38:193-259

43. The HYP Consortium (1995) A gene (PEX) with homologies to endopeptidases is mutated in patients with X-linked hypophosphatemic rickets. Nat Genet 11:130-136

44. Alon US (2011) Clinical practice. Fibroblast growth factor (FGF)23: a new hormone. Eur J Pediatr 170:545-554

45. Liu S, Zhou J, Tang W, Jiang X, Rowe DW, Quarles LD (2006) Pathogenic role of FGF23 in Hyp mice. Am J Physiol Endocrinol Metab 291:E38-E49

46. David V, Martin A, Hedge AM, Drezner MK, Rowe PS (2011) ASARM peptides: PHEX-dependent and -independent regulation of serum phosphate. Am J Physiol Renal Physiol 300:F783-F791

47. Liang G, Katz LD, Insogna KL, Carpenter TO, Macica CM (2009) Survey of the enthesopathy of X linked hypophosphatemia and its characterization in Hyp mice. Calcif Tiss Int 85:235-246

48. Chaussain-Miller C, Sinding C, Septier D, Wolikow M, Goldberg M, Garabedian M (2007) Dentin structure in familial hypophosphatemic rickets: benefits of vitamin D and phosphate treatment. Oral Dis 13:482-489

49. Linglart A, Biosse-Duplan M, Briot K, Chaussain C, Esterle L, Guillaume-Czitrom S, Kamenicky P, Nevoux J, Prié D, Rothenbuhler A, Wicart P, Harvengt P (2014) Therapeutic management of hypophosphatemic rickets from infancy to adulthood. Endocr Connect 3:R13-R30

50. Iguchi A, Yamamoto S, Yamazaki M, Tasaki K, Suzuki Y, Kazama JJ, Narita I (2017) Effect of ferric citrate hydrate on FGF23 and PTH levels in patients with non-dialysis-dependent chronic kidney disease with normophosphatemia and iron deficiency. Clin Exp Nephrol. https://doi.org/10.1007/s10157-017-1510-x

51. Shimizu Y, Tada Y, Yamauchi M, Okamoto T, Suzuki H, Ito N, Fukumoto S, Sugimoto T, Fujita T (2009) Hypophosphatemia induced by intravenous administration of saccharated ferric oxide: another form of FGF23-related hypophosphatemia. Bone. 45:814-6

52. Huang X, Jiang Y, Xia W (2013) FGF23 and phosphate wasting disorders. Bone 28:120-132

53. Imel EA, Econs MJ (2005) Fibroblast growth factor 23: roles in health and disease. J Am Soc Nephrol 16:2565-2575

54. Econs MJ, McEnery PT (1997) Autosomal dominant hypophosphatemic rickets/osteomalacia: clinical characterization of a novel renal phosphate-wasting disorder. J Clin Endocrinol Metab 82:674-681

55. Imel EA, Peacock M, Gray AK, Padgett LR, Hui SL, Econs MJ (2011) Iron modifies plasma FGF23 differently in autosomal dominant hypophosphatemic rickets and healthy humans. J Clin Endocrinol Metab 96:3541-3549

56. Imel EA, Hui SL, Econs MJ (2007) FGF23 concentrations vary with disease status in autosomal dominant hypophosphatemic rickets. J Bone Miner Res 22:520-526

57. Levy-Litan V, Hershkovitz E, Avizov L, Leventhal N, Bercovich D, Chalifa-Caspi V, Manor E, Buriakovsky S, Hadad Y, Goding J, Parvari R (2010) Autosomal-recessive hypophosphatemic rickets is associated with an inactivation mutation in the ENPP1 gene. Am J Hum Genet 86:273-278

58. Lorenz-Depiereux B, Benet-Pages A, Eckstein G, TenenbaumRakover Y, Wagenstaller J, Tiosano D, Gershoni-Baruch R, Albers N, Lichtner P, Schnabel D, Hochberg Z', Strom TM (2006) Hereditary hypophosphatemic rickets with hypercalciuria is caused by mutations in the sodium-phosphate cotransporter gene SLC34A3. Am J Hum Genet 78:193-201

59. Haito-Sugino S, Ito M, Ohi A, Shiozaki Y, Kangawa N, Nishiyama T, Aranami F, Sasaki S, Mori A, Kido S, Tatsumi S, Segawa H, Miyamoto KI (2012) Processing and stability of type IIc sodium-dependent phosphate cotransporter mutations in patients with hereditary hypophosphatemic rickets with hypercalciuria. Am J Physiol Cell Physiol 302:C1316-C1330

60. Jaureguiberry G, Carpenter TO, Forman S, Harald Jüppner H, Bergwitz C (2008) A novel missense mutation in SLC34A3 that causeshereditary hypophosphatemic rickets with hypercalciuria inhumans identifies threonine 137 as an important determinant ofsodium-phosphate cotransport in NaPi-IIc. Am J Physiol Renal Physiol 295:F371-F379

61. Riminucci M, Collins MT, Fedarko NS, Cherman N, Corsi A, White KE, Waguespack S, Gupta A, Hannon T, Econs MJ, Bianco P, Gehron Robey P (2003) FGF-23 in fibrous dysplasia of bone and its relationship to renal phosphate wasting. J Clin Invest 112:683-692

62. Lee JY, Imel EA (2013) The changing face of hypophosphatemic disorders in the FGF-23 era. Pediatr Endocrinol Rev 2:367-379

63. Bhattacharyya N, Wiench M, Dumitrescu C, Connolly BM, Bugge TH, Patel HV, Gafni RI, Cherman N, Cho M, Hager GL, Collins MT (2012) Mechanism of FGF23 processing in fibrous dysplasia. J Bone Miner Res 27:1132-1141

64. Folpe AL, Fanburg-Smith JC, Billings SD, Bisceglia M, Bertoni F, Cho JY, Econs MJ, Inwards CY, Jan de Beur SM, Mentzel T, Montgomery E, Michal M, Miettinen M, Mills SE, Reith JD, O'Connell JX, Rosenberg AE, Rubin BP, Sweet DE, Vinh TN, Wold LE, Wehrli BM, White KE, Zaino RJ, Weiss SW (2004) Most osteomalacia-associated mesenchymal tumors are a single histopathologic entity: an analysis of 32 cases and a comprehensive review of the literature. Am J Surg Pathol 28:1-30

65. Sun Z, Jin J, Qiu G, Gao P, Liu Y (2015) Surgical treatment of tumor-induced osteomalacia: a retrospective review of 40 cases with extremity tumors. BMC Musculoskelet Disord 16:43

66. Duet M, Kerkeni S, Sfar R, Bazille C, Lioté F, Orcel P (2008) Clinical impact of somatostatin receptor scintigraphy in the management of tumor-induced osteomalacia. Clin Nucl Med $33: 752-756$

67. Hautmann AH, Schroeder J, Wild P, Hautmann MG, Huber E, Hoffstetter P et al (2014) Tumor-induced osteomalacia: increased level of FGF-23 in a patient with a phosphaturic mesenchymal tumor at the tibia expressing periostin. Case Rep Endocrinol 2014:729387

68. Stark H, Eisenstein B, Tieder M, Rachmel A, Alpert G (1986) Direct measurement of TP/ GFR: a simple and reliable parameter of renal phosphate handling. Nephron 44:125-128

69. Endo I, Fukumoto S, Ozono K, Namba N, Tanaka H, Inoue D, Minagawa M, Sugimoto T, Yamauchi M, Michigami T, Matsumoto T (2008) Clinical usefulness of measurement of fibroblast growth factor 23 (FGF23) in hypophosphatemicpatients: proposal of diagnostic criteria using FGF23 measurement. Bone 42:1235-1239

70. Igaki JM, Yamada M, Yamazaki Y, Koto S, Izawa M, Ariyasu D, Suzuki E, Hasegawa H, Hasegawa Y (2011) High iFGF23 level despite hypophosphatemia is one of the clinical indicators to make diagnosis of XLH. Endocr J 58:647-655

71. Harrell RM, Lyles KW, Harrelson JM, Friedman NE, Drezner MK (1985) Healing of bone disease in X-linked hypophosphatemic rickets/osteomalacia. Induction and maintenance with phosphorus and calcitriol. J Clin Invest 75:1858-1868

74. Perwad F, Azam N, Zhang MY et al (2005) Dietary and serum phosphorus regulate fibroblast growth factor 23 expression and 1 , 25-dihydroxyvitamin D metabolism in mice. Endocrinology 146: 5358-5364

73. Baroncelli GI, Bertelloni S, Ceccarelli C, Saggese G (2001) Effect of growth hormone treatment on final height, phosphate metabolism, and bone mineral density in children with X-linked hypophosphatemic rickets. J Pediatr 138:236-243 20

74. Haffner D, Nissel R, Wuh E, Mehls O (2004) Effects of growth hormone treatment on body proportions and final height among 
small children with $\mathrm{X}$-linked hypophosphatemic rickets. Pediatrics 113:e593-e596

75. Saggese G, Baroncelli G, Bertelloni S, Perri G (1995) Long-term growth hormone treatment in children with renal hypophosphatemic rickets: effects on growth, mineral metabolism, and bone density. J Pediatr 127:395-402

76. Živičnjak M, Schnabel D, Staude H, Even G, Marx M, Beetz R, Holder M, Billing H, Fischer DC, Rabl W, Schumacher M, Hiort O, Haffner D, Hypophosphatemic Rickets Study Group of the Arbeitsgemeinschaft für Pädiatrische Endokrinologie and Gesellschaft für Pädiatrische Nephrologie (2011) Three-year growth hormone treatment in short children with X-linked hypophosphatemic rickets: effects on linear growth and body disproportion. J Clin Endocrinol Metab 96:E2097-E2105

77. Meyerhoff N, Haffner D, Staude H, Wühl E, Marx M, Beetz R, Querfeld U, Holder M, Billing H, Rabl W, Schröder C, Hiort O, Brämswig JH, Richter-Unruh A, Schnabel D, Živičnjak M, Hypophosphatemic Rickets Study Group of the "Deutsche Gesellschaft für Kinderendokrinologie und -diabetologie" and "Gesellschaft für Pädiatrische Nephrologie" (2018) Effects of growth hormone treatment on adult height in severely short children with X-linked hypophosphatemic rickets. Pediatr Nephrol 33:447-456

78. Eyres KS, Brown J, Douglas DL (1993) Osteotomy and intramedullary nailing for the correction of progressive deformity in vitamin D-resistant hypophosphatemic rickets. J R Coll Surg Edinb 38:50-54

79. Komaba H, Koizumi M, Tanaka H et al (2011) Effects of cinacalcet treatment on serum soluble Klotho levels in haemodialysis patients with secondary hyperparathyroidism. Nephrol Dial Transplant 27:1967-1969

80. Nemeth EF, Heaton WH, Miller M, Fox J, Balandrin MF, Van Wagenen BC, Colloton M, Karbon W, Scherrer J, Shatzen E, Rishton G, Scully S, Qi M, Harris R, Lacey D, Martin D (2004) Pharmacodynamics of the type II calcimimetic compound cinacalcet HCl. J Pharmacol Exp Ther 308:627-635

81. Alon US, Levy-Olomucki R, Moore WV, Stubbs J, Liu S, Quarles LD (2008) Calcimimetics as an adjuvant treatment for familial hypophosphatemic rickets. Clin J Am Soc Nephrol 3:658-664

82. Yavropoulou MP, Kotsa K, Gotzamani Psarrakou A, Papazisi A, Tranga T, Ventis S, Yovos JG (2010) Cinacalcet in hyperparathyroidism secondary to $\mathrm{X}$-linked hypophosphatemic rickets: case report and brief literature review. Hormones (Athens) 9:274-278

83. Leifheit-Nestler M, Kucka J, Yoshizawa E, Behets G, D'Haese P, Bergen C, Meier M, Fischer DC, Haffner D (2017) Comparison of calcimimetic R568 and calcitriol in mineral homeostasis in the Hyp mouse, a murine homolog of X-linked hypophosphatemia. Bone 103:224-232

84. Liu ES, Carpenter TO, Gundberg CM et al (2011) Calcitonin administration in X-linked hypophosphatemia. N Engl J Med 364:1678-1680

85. Data available: European agency medicine (2012) Calcitonin. http:/www.ema.europa.eu/ema/index.jspcurl=pages/medicines/ human/referrals/Calcitonin/human_referral_000319.jsp\&mid= WC0b01ac0580024e99. Accessed 31 May 2018

86. FDA (2015) Questions and Answers: Changes to the Indicated Population for Miacalcin (calcitonin-salmon). https://www.fda.gov/Drugs/Drug S a fety/ PostmarketDrugSafetyInformationforPatientsandProviders/ ucm388641.htm. Accessed 31 May 2018
87. Yamazaki Y, Tamada T, Kasai N, Urakawa I, Aono Y, Hasegawa H, Fujita T, Kuroki R, Yamashita T, Fukumoto S, Shimada T (2008) Anti-FGF23 neutralizing antibodies show the physiological role and structural features of FGF23. J Bone Miner Res 23:1509-1518

88. Aono Y, Hasegawa H, Yamazaki Y, Shimada T, Fujita T, Yamashita T, Fukumoto S (2011) Anti-FGF23 neutralizing antibodies ameliorate muscle weakness and decreased spontaneous movement of Hyp mice. J Bone Miner Res 26:803-810

89. ClinicalTrials.gov identifiers NCT00830674

90. ClinicalTrials.gov identifiers NCT01340482

91. ClinicalTrials.gov identifiers NCT01571596

92. Carpenter TO, Imel EA, Ruppe MD, Weber TJ, Klausner MA, Wooddell MM, Kawakami T, Ito T, Zhang X, Humphrey J, Insogna KL, Peacock M (2014) Randomized trial of the antiFGF23 antibody KRN23 in X-linked hypophosphatemia. J Clin Invest 124:1587-1597

93. Zhang X, Carpenter T, Imel E et al (2013) Pharmacokinetics and pharmacodynamics of a human monoclonal anti-FGF23 antibody (KRN23) after single-dose administration to patients with Xlinked hypophosphatemia. J Bone Miner Res 28(uppl 1):SU0169

94. Imel EA, Zhang X, Ruppe MD, Weber TJ, Klausner MA, Ito T, Vergeire M, Humphrey JS, Glorieux FH, Portale AA, Insogna K, Peacock M, Carpenter TO (2015) Prolonged correction of serum phosphorus in adults with $\mathrm{X}$-linked hypophosphatemia using monthly doses of KRN23. J Clin Endocrinol Metab 10:2565-2573

94. Ruppe MD, Zhang X, Imel EA, Weber TJ, Klausner MA, Ito T, Vergeire M, Humphrey JS, Glorieux FH, Portale AA, Insogna K, Peacock M, Carpenter TO (2016) Effect of four monthly doses of a human monoclonal anti-FGF23 antibody (KRN23) on quality of life in X-linked hypophosphatemia. Bone Rep 13:158-162

96. Minisola S, Peacock M, Fukumoto S, Cipriani C, Pepe J, Tella HT, Collins MT (2017) Tumor-induced osteomalacia. Nat Rev Dis Primers 13(3): 17044

97. Khosravi A, Cutler CM, Kelly MH, Chang R, Royal RE, Sherry RM, Wodajo FM, Fedarko NS, Collins MT (2007) Determination of the elimination half-life of fibroblast growth factor-23. Journal of Clinical Endocrinology \& Metabolism 92:2374-2377

98. Harvey JN, Gray C, Belchetz PE (1992) Oncogenous osteomalacia and malignancy. Clin Endocrinol 37:379-382

99. Hesse E, Rosenthal H, Bastian L (2007) Radiofrequency ablation of a tumor causing oncogenic osteomalacia. N Engl J Med 357: $422-424$

100. Geller JL, Khosravi A, Kelly MH, Riminucci M, Adams JS, Collins MT (2007) Cinacalcet in the management of tumorinduced osteomalacia. J Bone Miner Res 22:931-937

101. van Boekel G, Ruinemans-Koerts J, Joosten F, Dijkhuizen P, van Sorge A, de Boer H (2008) Tumor producing fibroblast growth factor 23 localized by two-staged venous sampling. Eur J Endocrinol 158:431-437

102. Carpenter TO, Miller P, Weber T, et al. (2017) Effects of KRN23, and anti- FGF23 antibody, in patients with tumor induced osteomalacia and epidermal nevus syndrome: results from an ongoing phase 2 study. In: Annual Meeting of the American Society for Bone and Mineral Research 1098. Bone Reports 7,90-97 96 D

103. Fukumoto S (2016) FGF23-FGF receptor/Klotho pathway as a new drug target for disorders of bone and mineral metabolism. Calcif Tissue Int 98:334-340

104. Collins MT, Singer FR, Eugster E (2012) McCune-Albright syndrome and the extraskeletal manifestations of fibrous dysplasia. Orphanet J Rare Dis 7(Suppl 1):S4 